\title{
Bioactive Phenanthrene and Bibenzyl Derivatives from Dendrobium nobile Stems
}

Xue-Ming Zhou, ${ }^{\dagger}$ Cai-Juan Zheng, ${ }^{\dagger}$ Li-She Gan, ${ }^{\S}$ Guang-Ying Chen, ${ }^{*}{ }^{\dagger}$ Xiao-Peng

Zhang, ${ }^{\dagger}$ Xiao-Ping Song, ${ }^{*},{ }^{\dagger}$ Gao-Nan Li, ${ }^{\dagger}$ and Chong-Ge Sun ${ }^{\star}$

†Key Laboratory of Tropical Medicinal Plant Chemistry of Ministry of Education, Hainan Normal University, Haikou 571158, P. R. China

${ }^{\S}$ College of Pharmaceutical Science, Zhejiang University, Hangzhou 310058, P. R. China

*Hainan Boying orchid industrial development co., LTD, Haikou 570105, P. R. China 


\section{List of Supporting Information}

Figure S1. Chiral HPLC chromatogram of denobilone A

Figure S2. The ${ }^{1} \mathrm{H}-\mathrm{NMR}$ spectrum of denobilone A in acetone- $d_{6}$

Figure S3. The ${ }^{13} \mathrm{C}$-NMR spectrum of denobilone A in acetone- $d_{6}$

Figure S4. The DEPT spectrum of denobilone A in acetone- $d_{6}$

Figure S5. The HSQC spectrum of denobilone A in acetone- $d_{6}$

Figure S6. The HMBC spectrum of denobilone A in acetone- $d_{6}$

Figure S7. The ${ }^{1} \mathrm{H}-{ }^{1} \mathrm{H}$ COSY spectrum of denobilone A in acetone- $d_{6}$

Figure S8. The HRESIMS of (-)-denobilone A (1)

Figure S9. The HRESIMS of (+)-denobilone A (2)

Figure S10. B3LYP/aug-cc-pVDZ-SCRF optimized lowest energy 3D conformers of (-)-denobilone A (1).

Table S11. Calculated ECD data of (-)-denobilone A (1).

Figure S12. The ${ }^{1} \mathrm{H}-\mathrm{NMR}$ spectrum of compound $\mathbf{3}$ in MeOD

Figure S13. The ${ }^{13} \mathrm{C}$-NMR spectrum of compound 3 in MeOD

Figure S14. The DEPT spectrum of compound 3 in MeOD

Figure S15. The HSQC spectrum of compound 3 in MeOD

Figure S16. The HMBC spectrum of compound 3 in MeOD

Figure S17. The ${ }^{1} \mathrm{H}-{ }^{1} \mathrm{H}$ COSY spectrum of compound 3 in MeOD

Figure S18. The HRESIMS of compound 3

Figure S19. The ${ }^{1} \mathrm{H}-\mathrm{NMR}$ spectrum of compound 4 in MeOD

Figure S20. The ${ }^{13} \mathrm{C}-\mathrm{NMR}$ spectrum of compound 4 in $\mathrm{MeOD}$

Figure S21. The DEPT spectrum of compound 4 in MeOD

Figure S22. The HSQC spectrum of compound 4 in MeOD

Figure S23. The HMBC spectrum of compound 4 in MeOD

Figure S24. The ${ }^{1} \mathrm{H}-{ }^{1} \mathrm{H}$ COSY spectrum of compound 4 in $\mathrm{MeOD}$

Figure S25. The HRESIMS of compound 4

Figure S26. The ${ }^{1} \mathrm{H}-\mathrm{NMR}$ spectrum of compound $\mathbf{5}$ in acetone- $d_{6}$

Figure S27. The ${ }^{13} \mathrm{C}$-NMR spectrum of compound $\mathbf{5}$ in acetone- $d_{6}$

Figure S28. The HSQC spectrum of compound 5 in acetone- $d_{6}$

Figure S29. The HMBC spectrum of compound $\mathbf{5}$ in acetone- $d_{6}$

Figure S30. The ${ }^{1} \mathrm{H}-{ }^{1} \mathrm{H}$ COSY spectrum of compound 5 in acetone- $d_{6}$

Figure S31. The HRESIMS of compound 5

Figure S32. The ${ }^{1}$ H-NMR spectrum of compound 22 in Acetone- $d_{6}$

Figure S33. The ${ }^{13} \mathrm{C}-\mathrm{NMR}$ spectrum of compound 22 in Acetone- $d_{6}$

Figure S34. The DEPT spectrum of compound 22 in Acetone- $d_{6}$

Figure S35. The HSQC spectrum of compound 22 in Acetone- $d_{6}$

Figure S36. The HMBC spectrum of compound 22 in Acetone- $d_{6}$

Figure S37. The ${ }^{1} \mathrm{H}-{ }^{1} \mathrm{H}$ COSY spectrum of compound 22 in Acetone- $d_{6}$

Figure S38. The HRESIMS of compound 22

Figure S42. The ${ }^{1} \mathrm{H}-\mathrm{NMR}$ spectrum of compound 23 in Acetone- $d_{6}$

Figure S43. The ${ }^{13} \mathrm{C}-\mathrm{NMR}$ spectrum of compound 23 in Acetone- $d_{6}$

Figure S44. The DEPT spectrum of compound 23 in Acetone- $d_{6}$ 
Figure S45. The HSQC spectrum of compound 23 in Acetone- $d_{6}$ Figure S46. The HMBC spectrum of compound 23 in Acetone- $d_{6}$ Figure S47. The ${ }^{1} \mathrm{H}-{ }^{1} \mathrm{H}$ COSY spectrum of compound 23 in Acetone- $d_{6}$ Figure S49. The HRESIMS of compound 23

Figure S50. The ${ }^{1} \mathrm{H}-\mathrm{NMR}$ spectrum of compound $\mathbf{2 4}$ in Acetone- $d_{6}$ Figure S51. The ${ }^{13} \mathrm{C}-\mathrm{NMR}$ spectrum of compound 24 in Acetone- $d_{6}$ Figure S52. The DEPT spectrum of compound 24 in Acetone- $d_{6}$ Figure S53. The HSQC spectrum of compound 24 in Acetone- $d_{6}$ Figure S54. The HMBC spectrum of compound 24 in Acetone- $d_{6}$ Figure S55. The ${ }^{1} \mathrm{H}-{ }^{1} \mathrm{H}$ COSY spectrum of compound $\mathbf{2 4}$ in Acetone- $d_{6}$ Figure S56. The HRESIMS of compound 24

S57. The procedure of calculation ECD

S58. The antifungal bioassay 
Figure S1. Chiral HPLC chromatogram of denobilone A

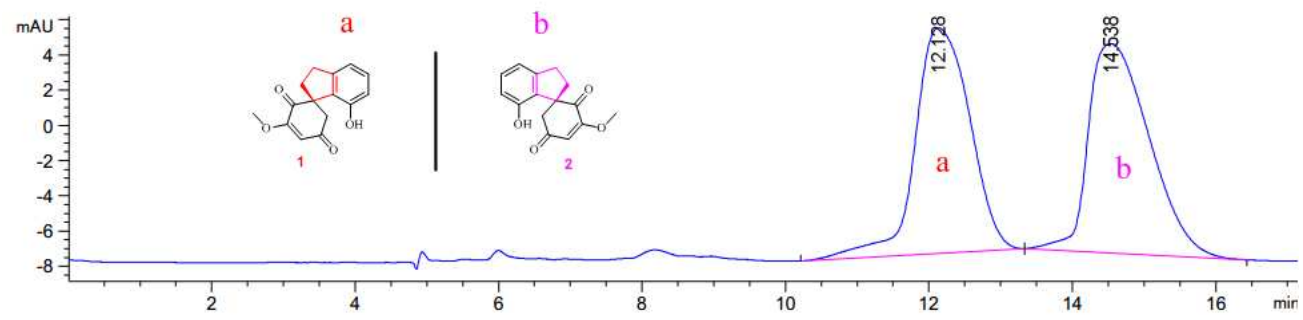

Column: ULTRON ES-OVM column $(150 \mathrm{~L} \times 10 \mathrm{~mm}, 5 \mu \mathrm{m})$

Mobile phase: $\mathrm{CH}_{3} \mathrm{CN} / \mathrm{H}_{2} \mathrm{O}(10: 90)$

Flow rate: $2 \mathrm{~mL} / \mathrm{min}$

Wavelength: $254 \mathrm{~nm}$

Figure S2. The ${ }^{1} \mathrm{H}-\mathrm{NMR}$ spectrum of denobilone A in acetone- $d_{6}$

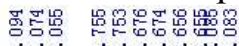

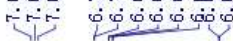

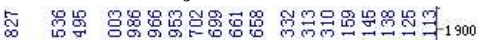
i) خ

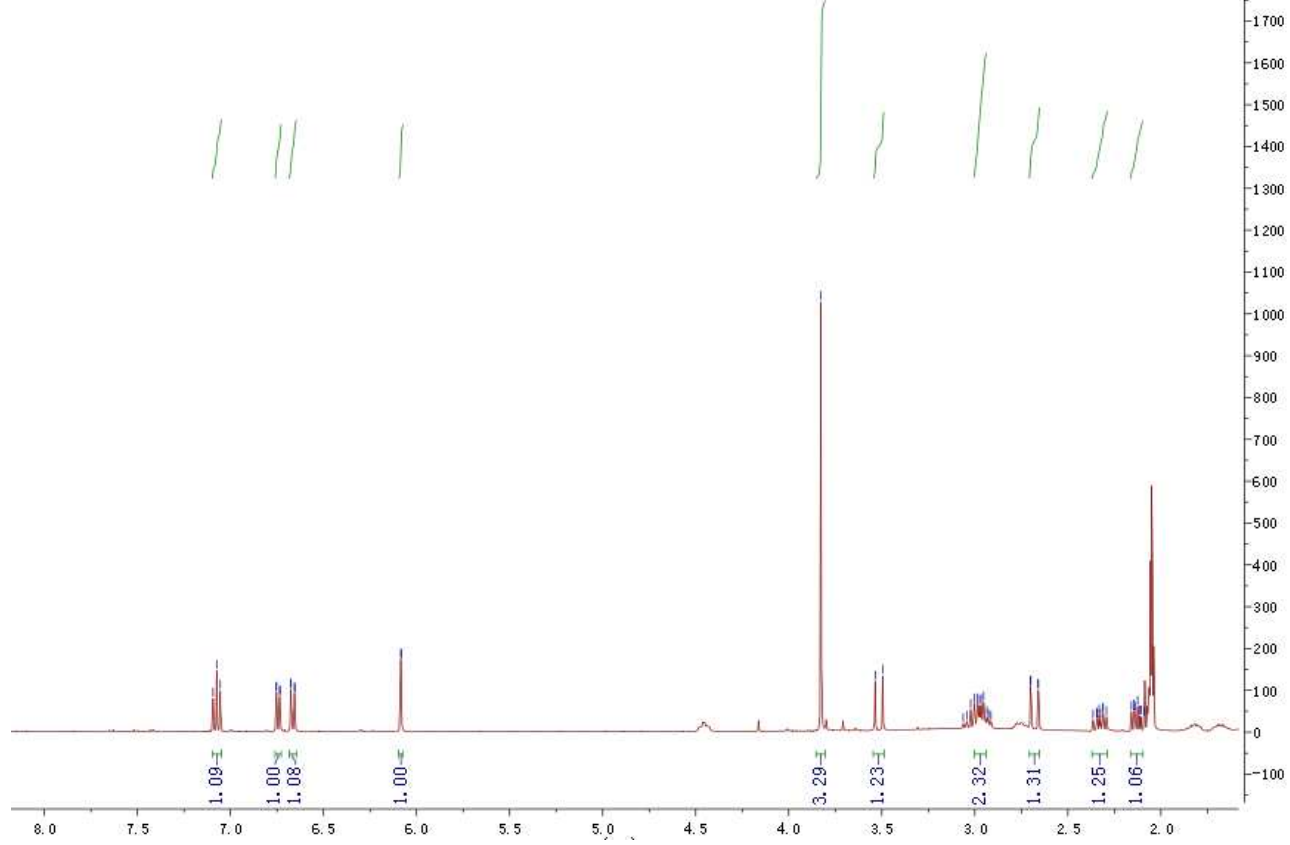


Figure S3. The ${ }^{13} \mathrm{C}$-NMR spectrum of denobilone A in acetone- $d_{6}$

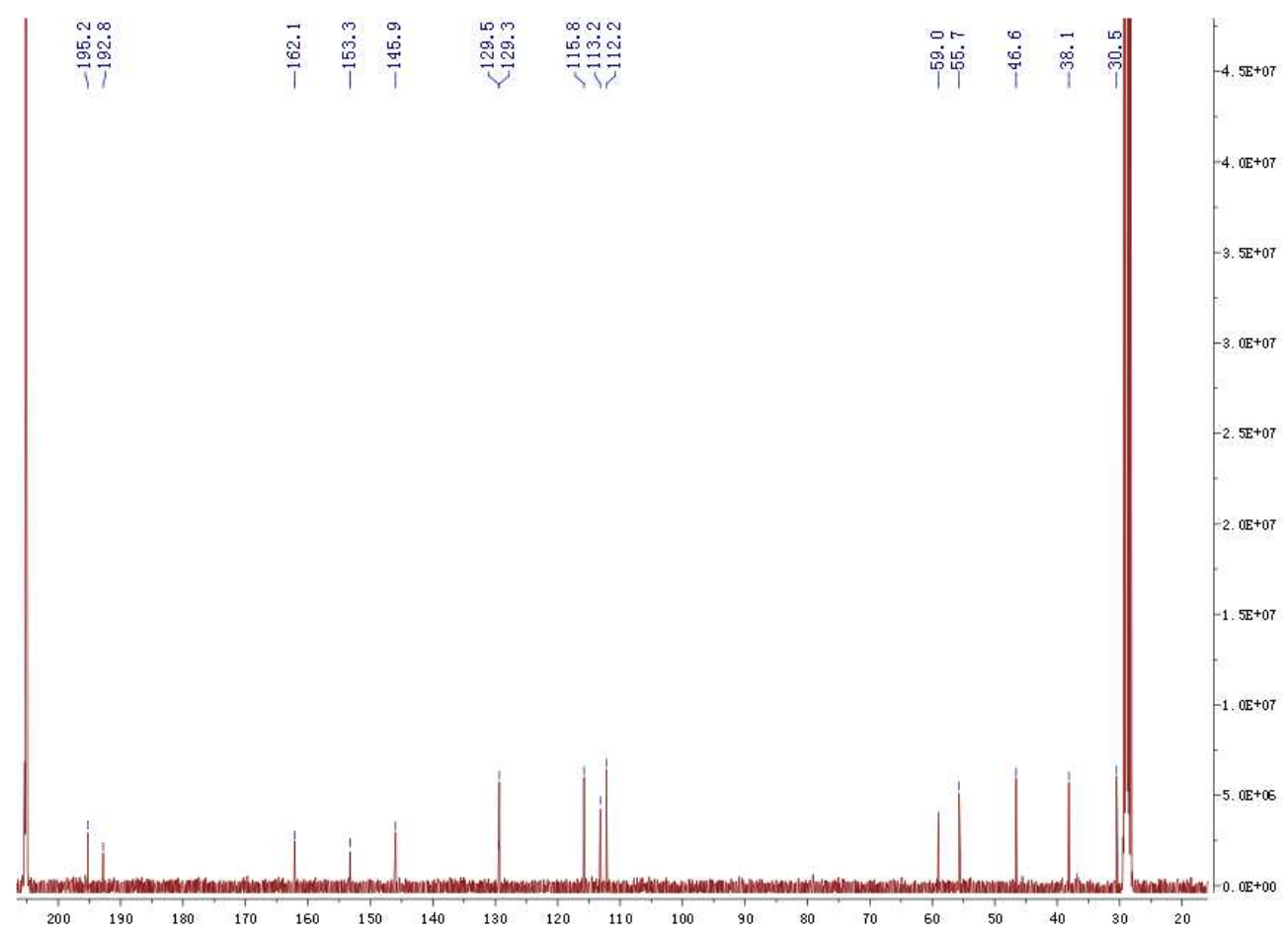

Figure S4. The DEPT spectrum of denobilone A in acetone- $d_{6}$

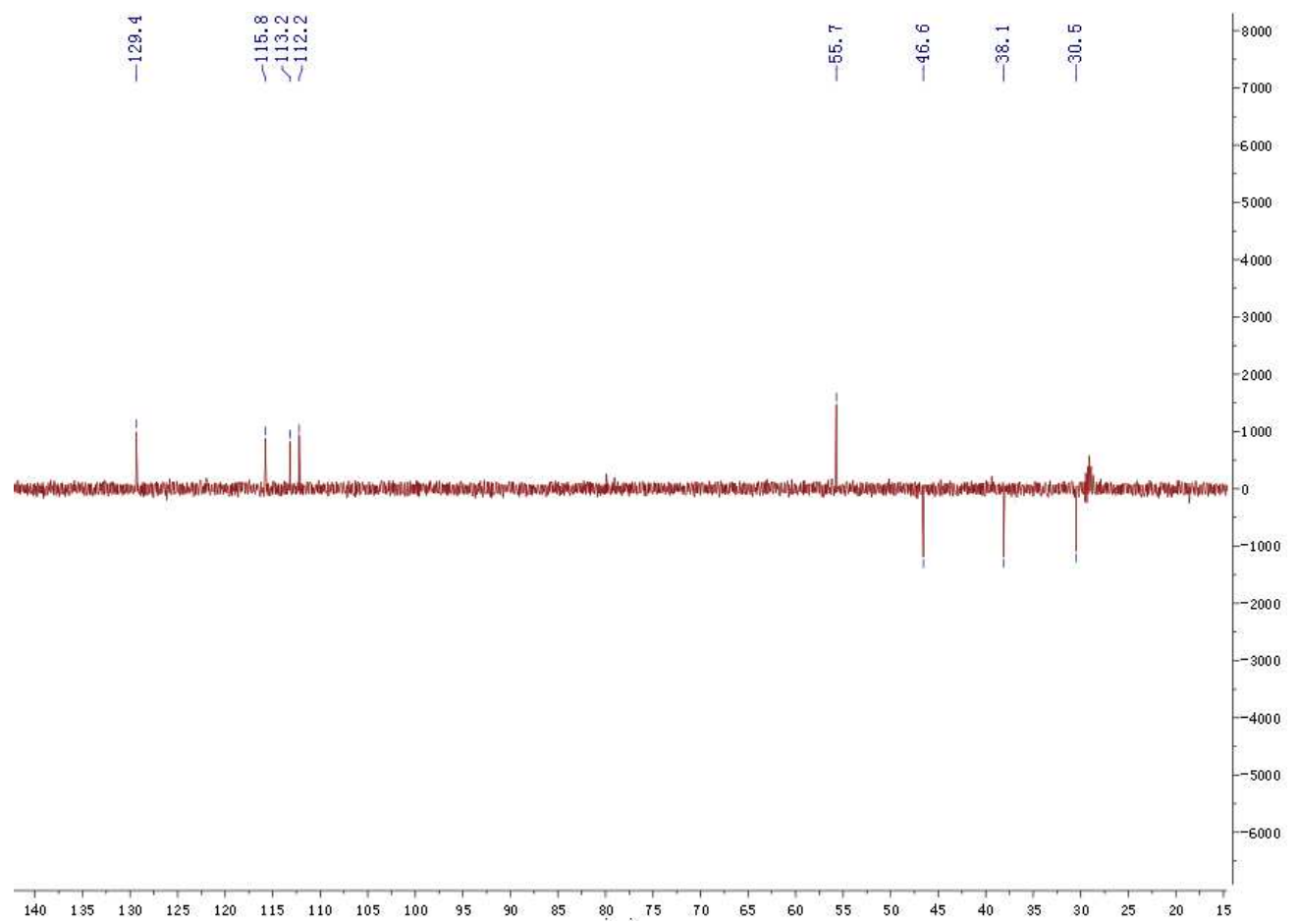


Figure S5. The HSQC spectrum of denobilone A in acetone- $d_{6}$

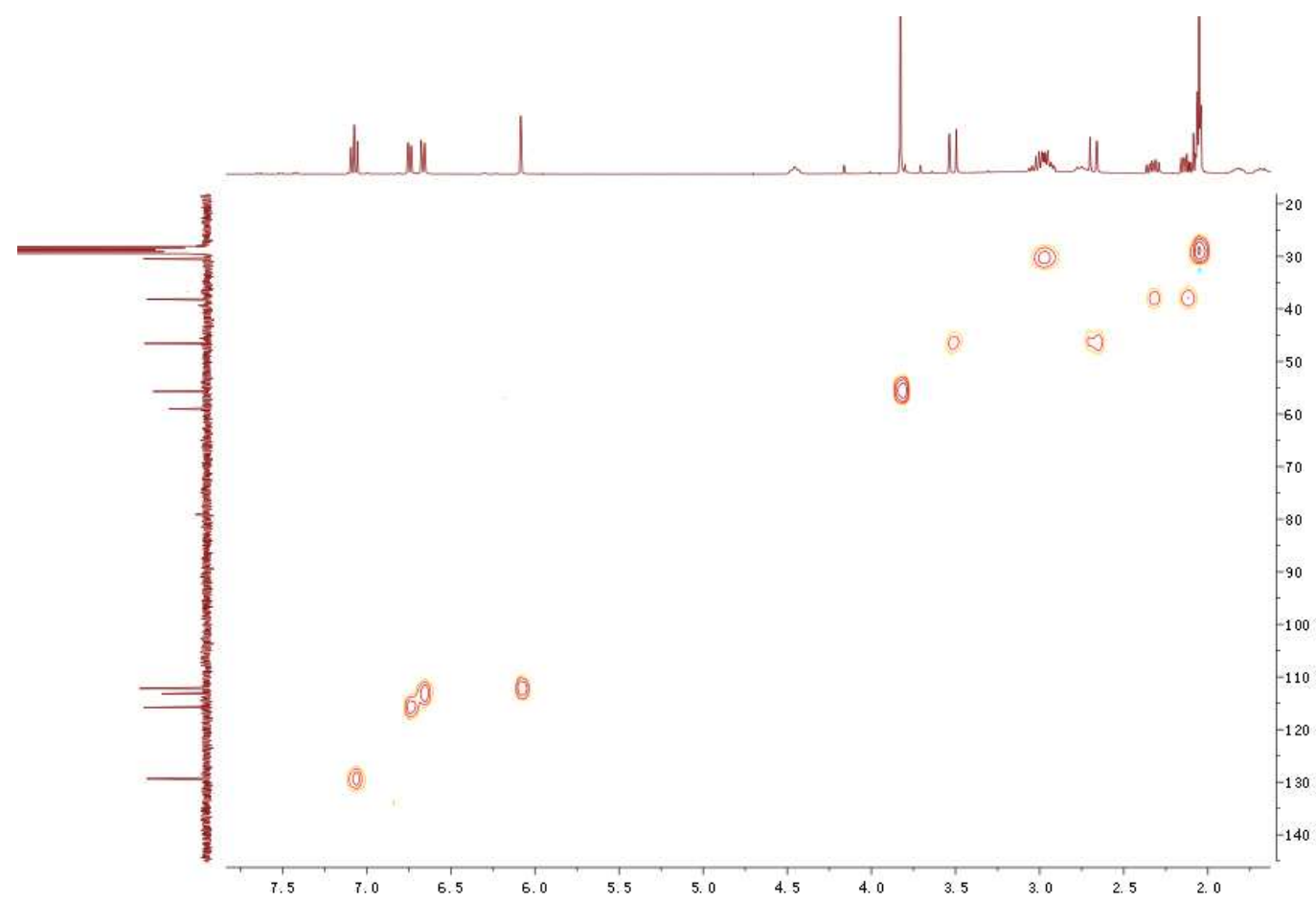

Figure S6. The HMBC spectrum of denobilone A in acetone- $d_{6}$

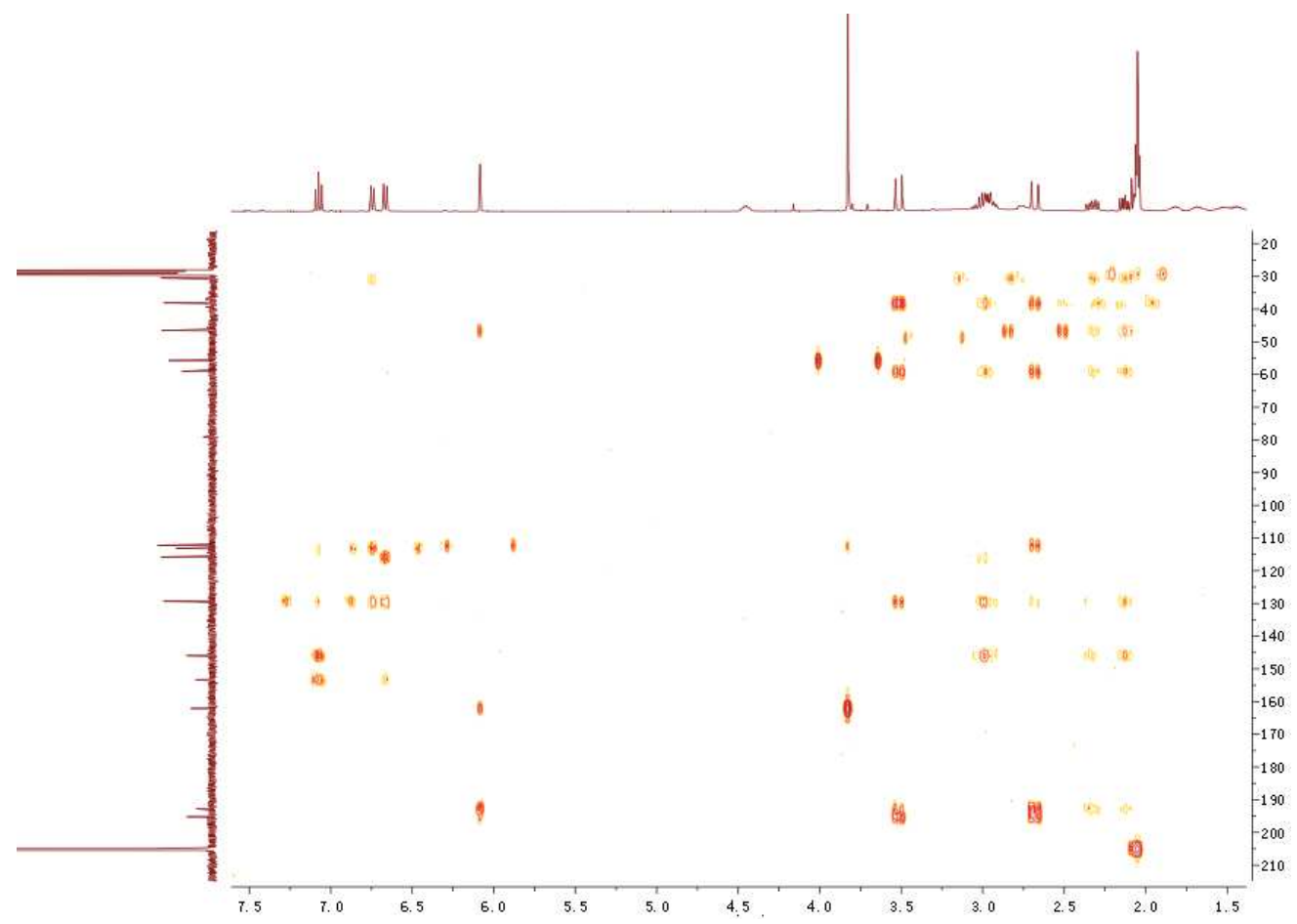


Figure S7. The ${ }^{1} \mathrm{H}-{ }^{1} \mathrm{H}$ COSY spectrum of denobilone A in acetone- $d_{6}$

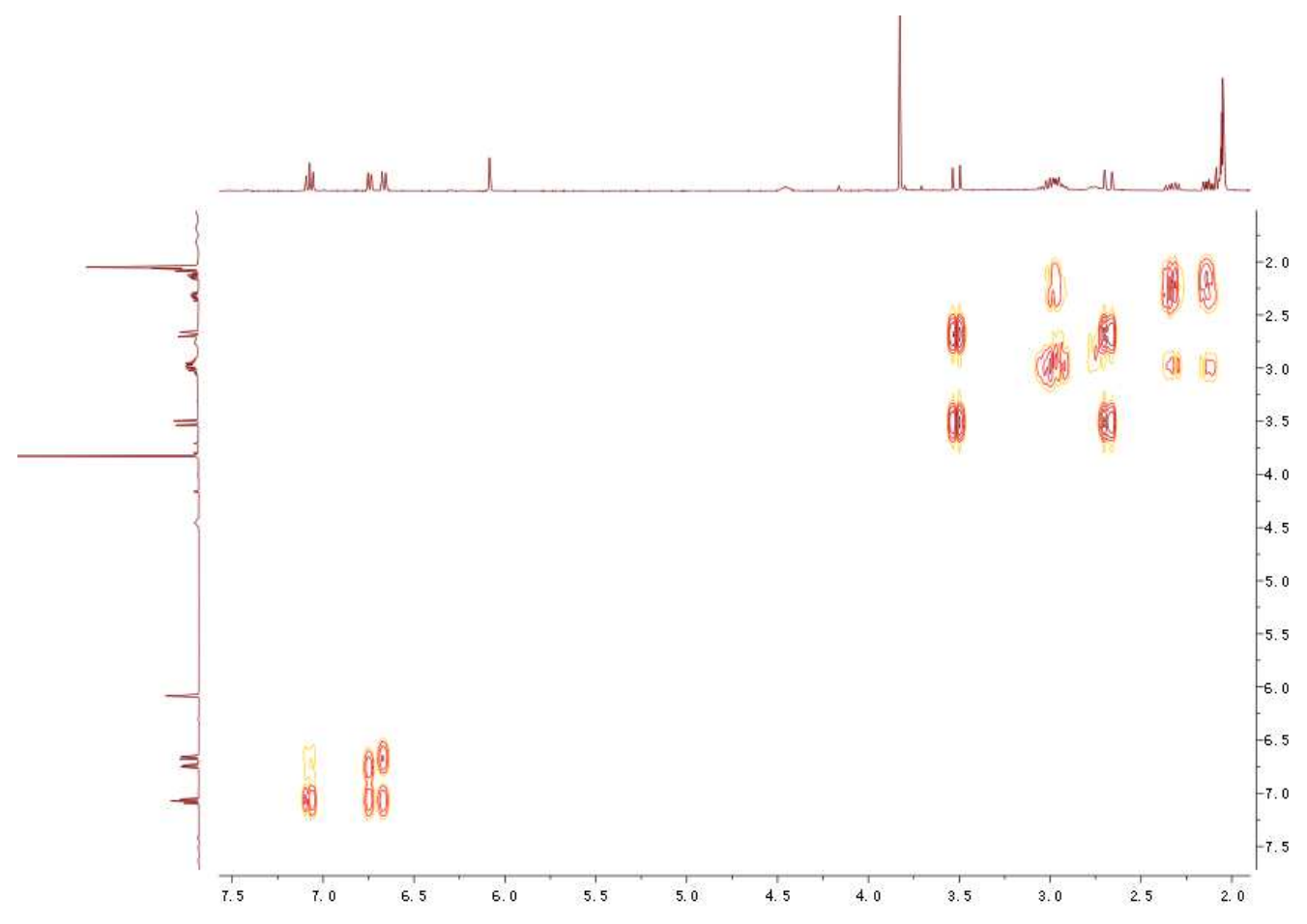

Figure S8. The HRESIMS of (+)-denobilone A (1)

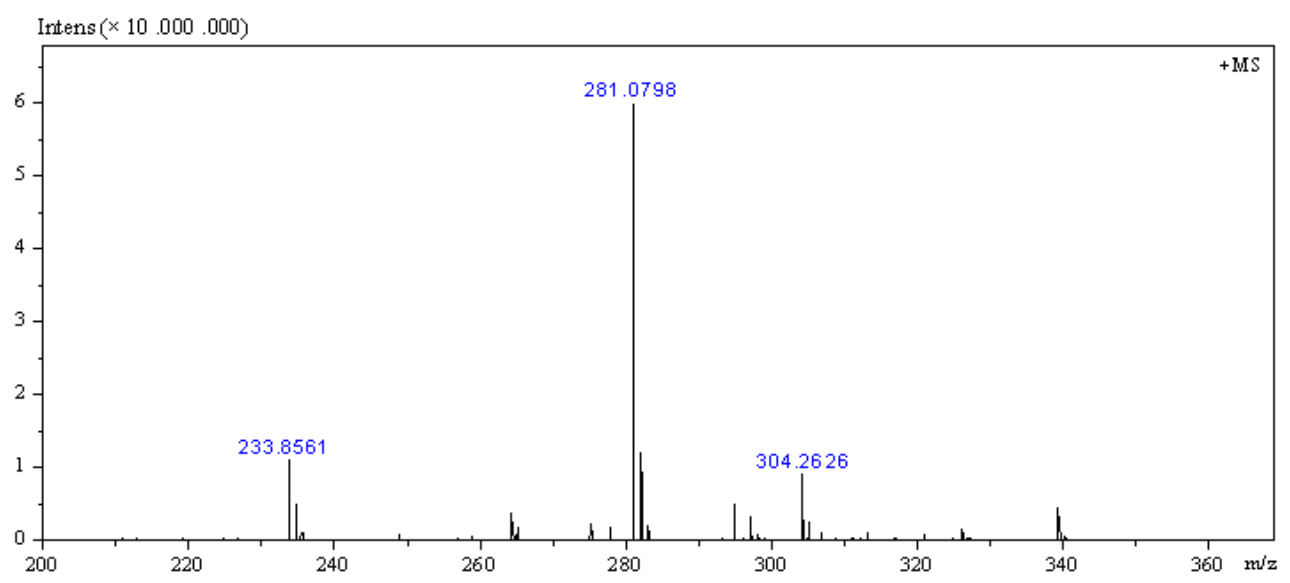


Figure S9. The HRESIMS of (-)-denobilone A (2)

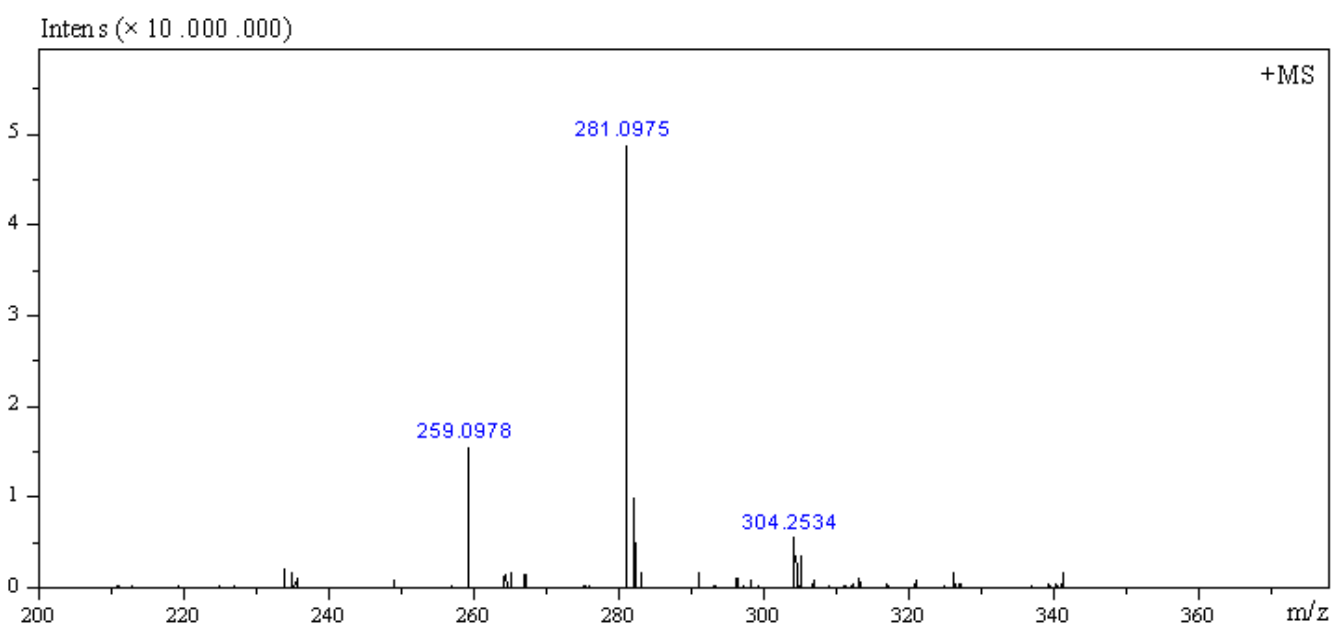

Figure S10. B3LYP/aug-cc-pVDZ-SCRF optimized lowest energy 3D conformers of (+)-denobilone A (1).

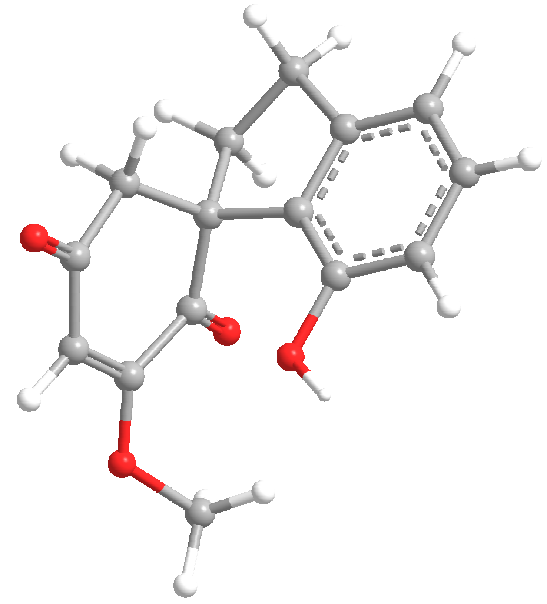

C1:4.54 kcal/mol

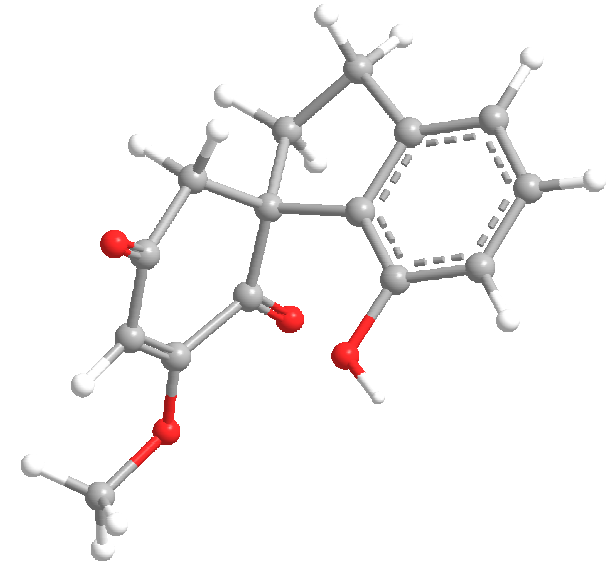

C2:0.00 kcal $/ \mathrm{mol}$

Table S11. Calculated ECD data of (+)-denobilone A (1).

\begin{tabular}{|r|l|r|r|r|r|}
\hline \multirow{2}{*}{ No } & \multicolumn{2}{|c|}{ 1C1 } & \multirow{2}{*}{ 1C2 } \\
\cline { 2 - 3 } \cline { 5 - 6 } & $\begin{array}{l}\text { Excitation } \\
\text { energies(eV) }\end{array}$ & $\begin{array}{l}\text { Rotatory } \\
\text { Strengths* }\end{array}$ & & $\begin{array}{l}\text { Excitation } \\
\text { energies(eV) }\end{array}$ & $\begin{array}{l}\text { Rotatory } \\
\text { Strengths* }\end{array}$ \\
\hline 1 & 2.9746 & 3.4104 & 1 & 3.0842 & -3.2595 \\
\hline 2 & 3.2814 & -5.4733 & 2 & 3.3764 & 10.3442 \\
\hline 3 & 3.3213 & 23.906 & 3 & 3.4362 & 3.2079 \\
\hline 4 & 3.6739 & 6.7271 & 4 & 3.7595 & -3.8953 \\
\hline 5 & 4.1079 & 3.4504 & 5 & 4.3089 & 36.7674 \\
\hline 6 & 4.8872 & -9.7958 & 6 & 4.9134 & 0.8209 \\
\hline 7 & 5.0855 & -0.4417 & 7 & 5.0845 & 6.5459 \\
\hline 8 & 5.2353 & -1.8049 & 8 & 5.2239 & 2.0887 \\
\hline 9 & 5.409 & -45.999 & 9 & 5.427 & -2.3052 \\
\hline 10 & 5.4207 & 0.5649 & 10 & 5.4756 & -19.0443 \\
\hline
\end{tabular}




\begin{tabular}{|c|c|c|c|c|c|}
\hline 11 & 5.5357 & 9.1619 & 11 & 5.5887 & 4.9461 \\
\hline 12 & 5.5804 & -5.9547 & 12 & 5.7185 & -1.8966 \\
\hline 13 & 5.661 & -2.2 & 13 & 5.79 & -38.24 \\
\hline 14 & 5.737 & -33.4102 & 14 & 5.8135 & -4.3991 \\
\hline 15 & 5.788 & -12.3923 & 15 & 5.8277 & -25.0451 \\
\hline 16 & 5.8279 & 11.2401 & 16 & 5.8874 & -34.8454 \\
\hline 17 & 5.8699 & -30.0772 & 17 & 5.9272 & -8.169 \\
\hline 18 & 5.9228 & 3.4321 & 18 & 5.9353 & -5.9896 \\
\hline 19 & 5.9459 & -10.3486 & 19 & 5.9989 & -23.4912 \\
\hline 20 & 5.9679 & -0.3903 & 20 & 6.0464 & 27.6004 \\
\hline 21 & 5.9995 & -21.3294 & 21 & 6.0768 & -4.187 \\
\hline 22 & 6.0542 & 0.4805 & 22 & 6.1334 & 0.2702 \\
\hline 23 & 6.0945 & -33.2345 & 23 & 6.1558 & -27.5341 \\
\hline 24 & 6.1357 & 158.5185 & 24 & 6.1743 & 6.7871 \\
\hline 25 & 6.149 & 9.1283 & 25 & 6.1965 & 71.727 \\
\hline 26 & 6.1879 & 31.0722 & 26 & 6.2083 & 33.4972 \\
\hline 27 & 6.2444 & -27.9408 & 27 & 6.2669 & 32.8874 \\
\hline 28 & 6.2609 & 7.8059 & 28 & 6.2849 & 15.756 \\
\hline 29 & 6.2759 & -3.57 & 29 & 6.3013 & -5.855 \\
\hline 30 & 6.2967 & -1.5702 & 30 & 6.3169 & 17.1795 \\
\hline 31 & 6.3121 & -2.7438 & 31 & 6.3572 & -13.3484 \\
\hline 32 & 6.3158 & -17.8672 & 32 & 6.3722 & 14.9259 \\
\hline 33 & 6.3459 & -17.0525 & 33 & 6.3815 & 24.8395 \\
\hline 34 & 6.3737 & 15.6389 & 34 & 6.3983 & -49.2118 \\
\hline 35 & 6.4151 & 0.1779 & 35 & 6.4633 & -19.4411 \\
\hline 36 & 6.426 & 12.5893 & 36 & 6.4866 & -26.0062 \\
\hline 37 & 6.4767 & -8.4289 & 37 & 6.5004 & 0.2818 \\
\hline 38 & 6.499 & 0.6441 & 38 & 6.5335 & 12.5926 \\
\hline 39 & 6.6183 & 1.3478 & 39 & 6.6206 & -11.0125 \\
\hline 40 & 6.6273 & -3.4161 & 40 & 6.627 & 3.8355 \\
\hline 41 & 6.6387 & 37.8876 & 41 & 6.6621 & 16.2766 \\
\hline 42 & 6.6507 & 4.4248 & 42 & 6.6734 & -1.531 \\
\hline 43 & 6.6598 & -17.4434 & 43 & 6.6907 & 13.9787 \\
\hline 44 & 6.673 & -66.3581 & 44 & 6.699 & 30.4807 \\
\hline 45 & 6.6841 & 36.1694 & 45 & 6.7113 & -6.8337 \\
\hline 46 & 6.7315 & 2.7 & 46 & 6.7245 & -20.1811 \\
\hline 47 & 6.746 & 1.2035 & 47 & 6.7445 & -0.8269 \\
\hline 48 & 6.7492 & 10.9768 & 48 & 6.7604 & 11.7891 \\
\hline 49 & 6.7691 & -4.3689 & 49 & 6.7739 & 8.8781 \\
\hline 50 & 6.7752 & -5.1835 & 50 & 6.8118 & -3.9809 \\
\hline 51 & 6.7848 & -5.5201 & 51 & 6.8239 & -13.3897 \\
\hline 52 & 6.8125 & -1.468 & 52 & 6.8544 & -11.2878 \\
\hline 53 & 6.8163 & 0.3086 & 53 & 6.8964 & 3.9303 \\
\hline 54 & 6.8714 & -8.6635 & 54 & 6.9129 & -4.6853 \\
\hline 55 & 6.9053 & 20.9765 & 55 & 6.923 & -6.81 \\
\hline 56 & 6.9474 & -1.5706 & 56 & 6.9945 & -6.2963 \\
\hline 57 & 6.9923 & -4.7909 & 57 & 7.0037 & 0.1825 \\
\hline 58 & 7.018 & -0.197 & 58 & 7.0341 & 3.1814 \\
\hline 59 & 7.1032 & -5.8233 & 59 & 7.0561 & 3.3402 \\
\hline 60 & 7.1072 & -4.2099 & 60 & 7.0767 & 0.8824 \\
\hline
\end{tabular}

* $\mathrm{R}$ (velocity) $10^{* *}-40$ erg-esu-cm 
Figure S12. The ${ }^{1} \mathrm{H}-\mathrm{NMR}$ spectrum of compound 3 in MeOD

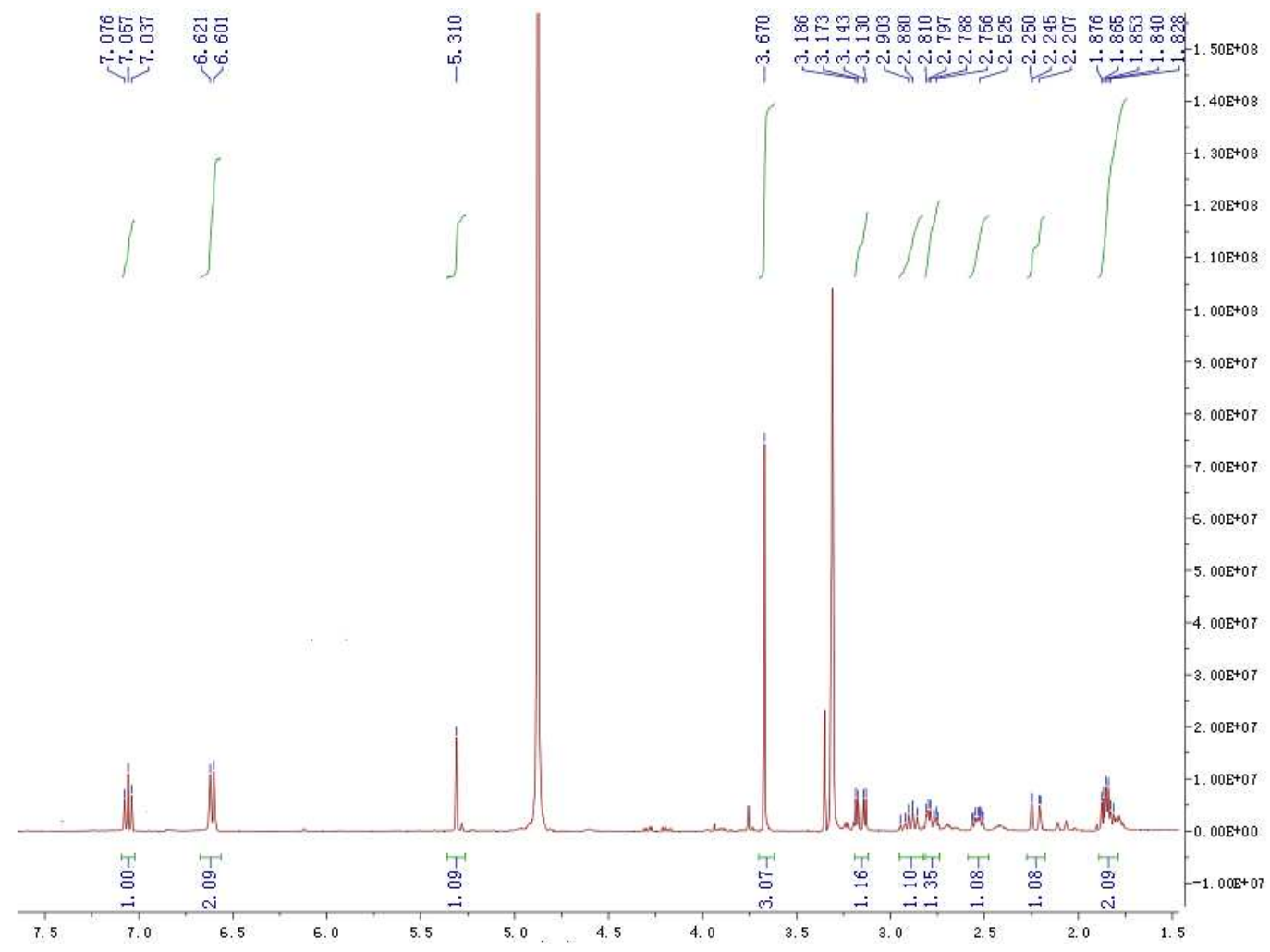

Figure S13. The ${ }^{13} \mathrm{C}-\mathrm{NMR}$ spectrum of compound 3 in $\mathrm{MeOD}$

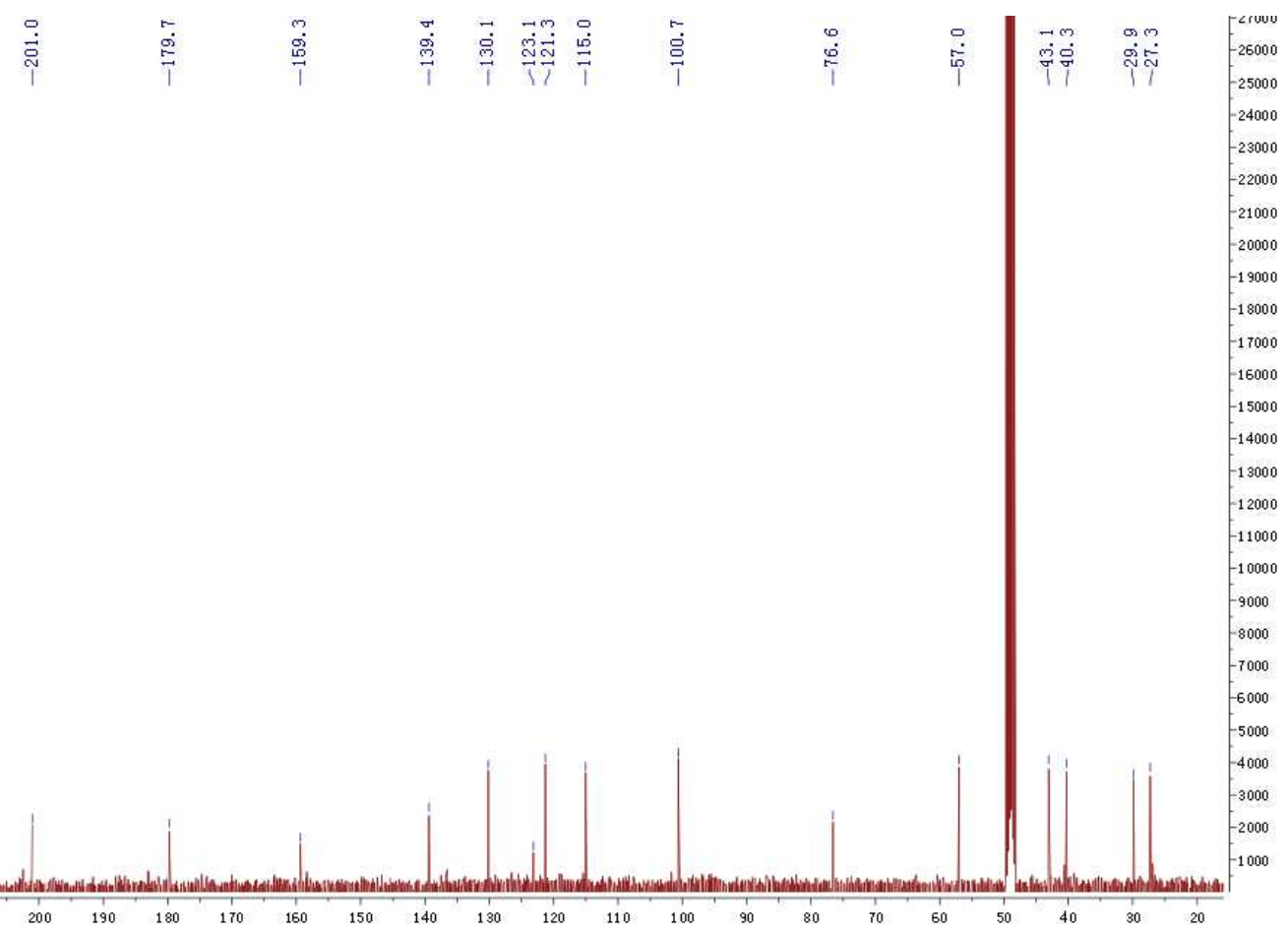


Figure S14. The DEPT spectrum of compound 3 in GeOD

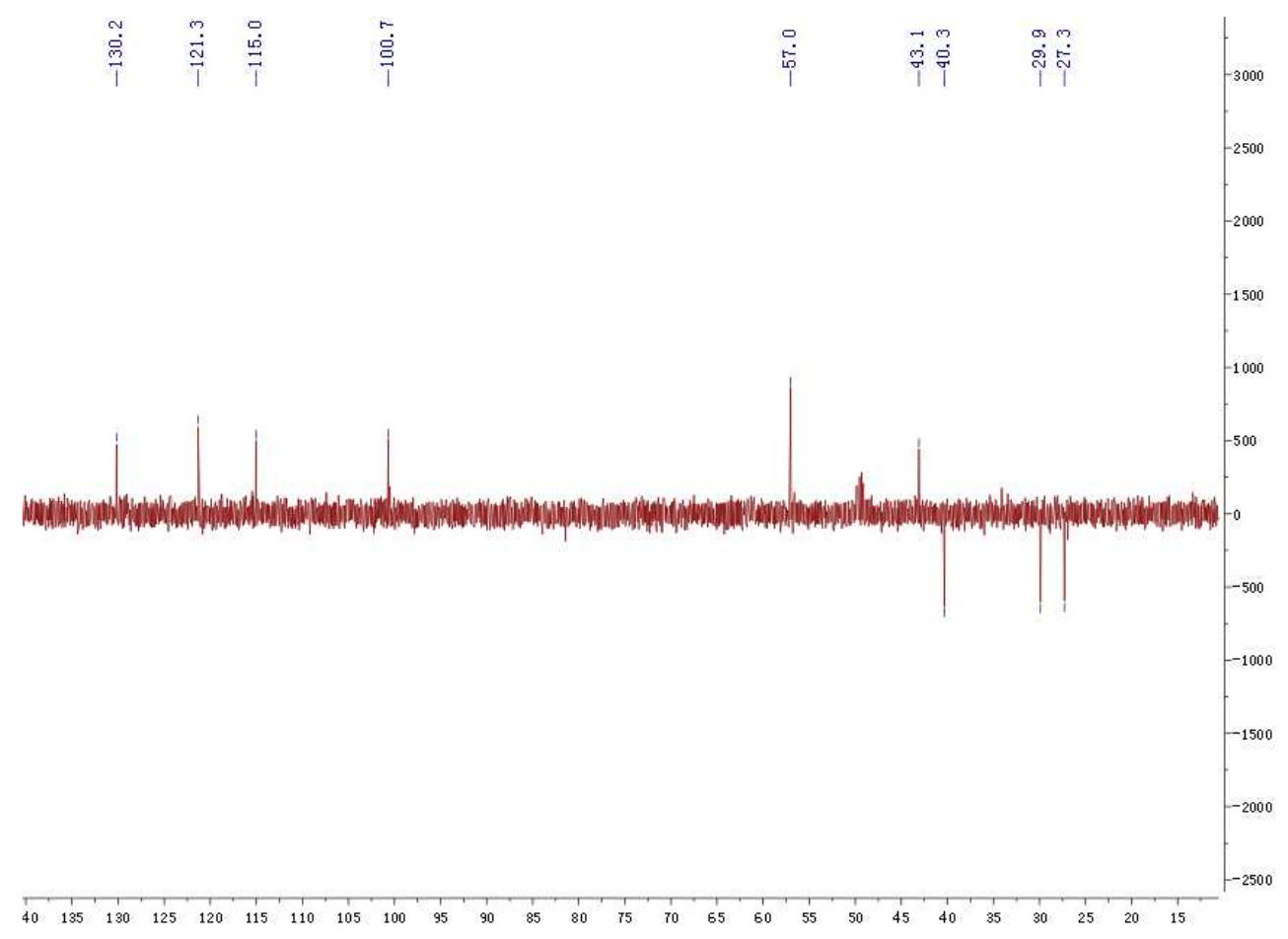

Figure S15. The HSQC spectrum of compound 3 in GeOD

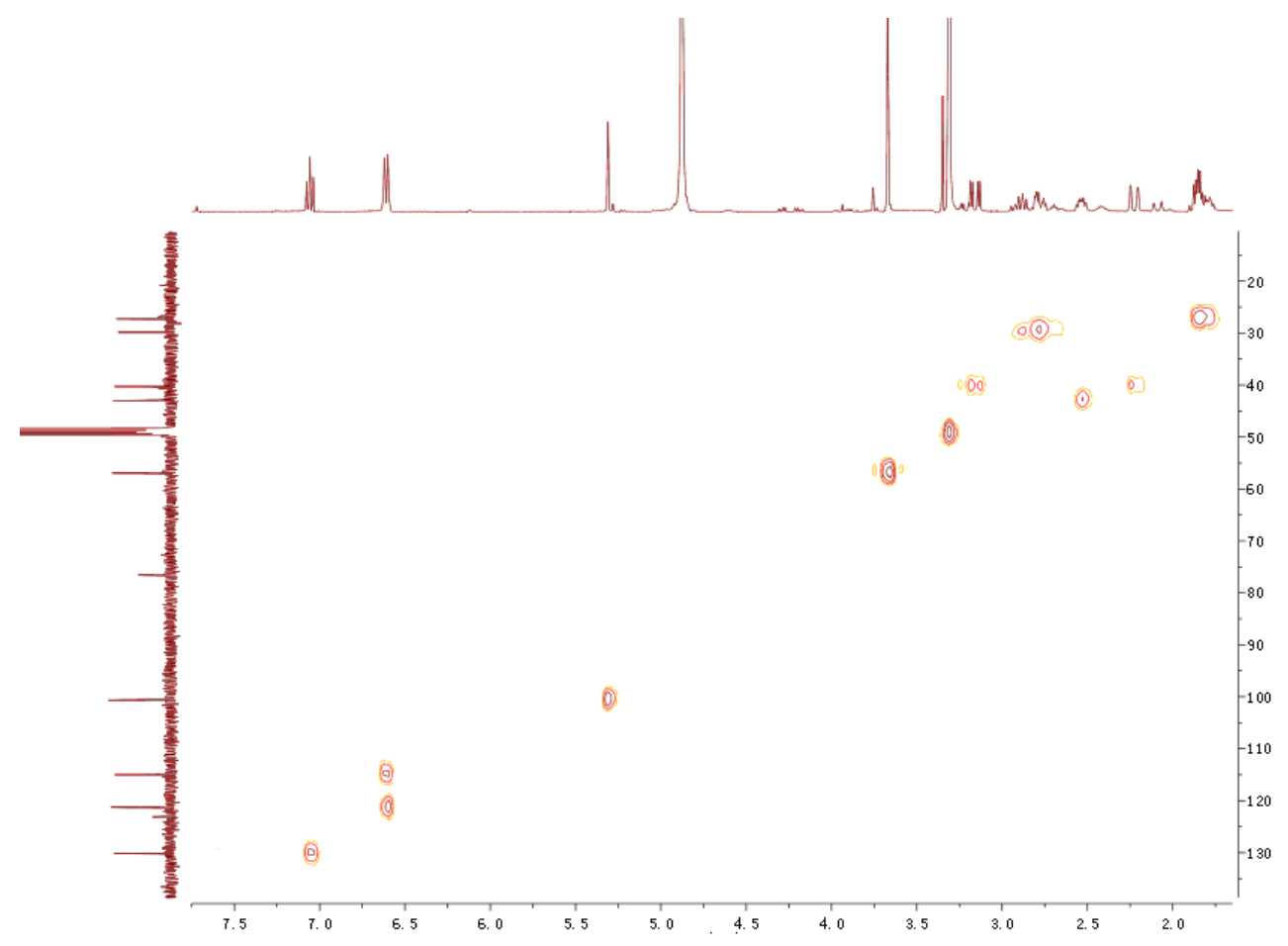


Figure S16. The HMBC spectrum of compound 3 in MeOD

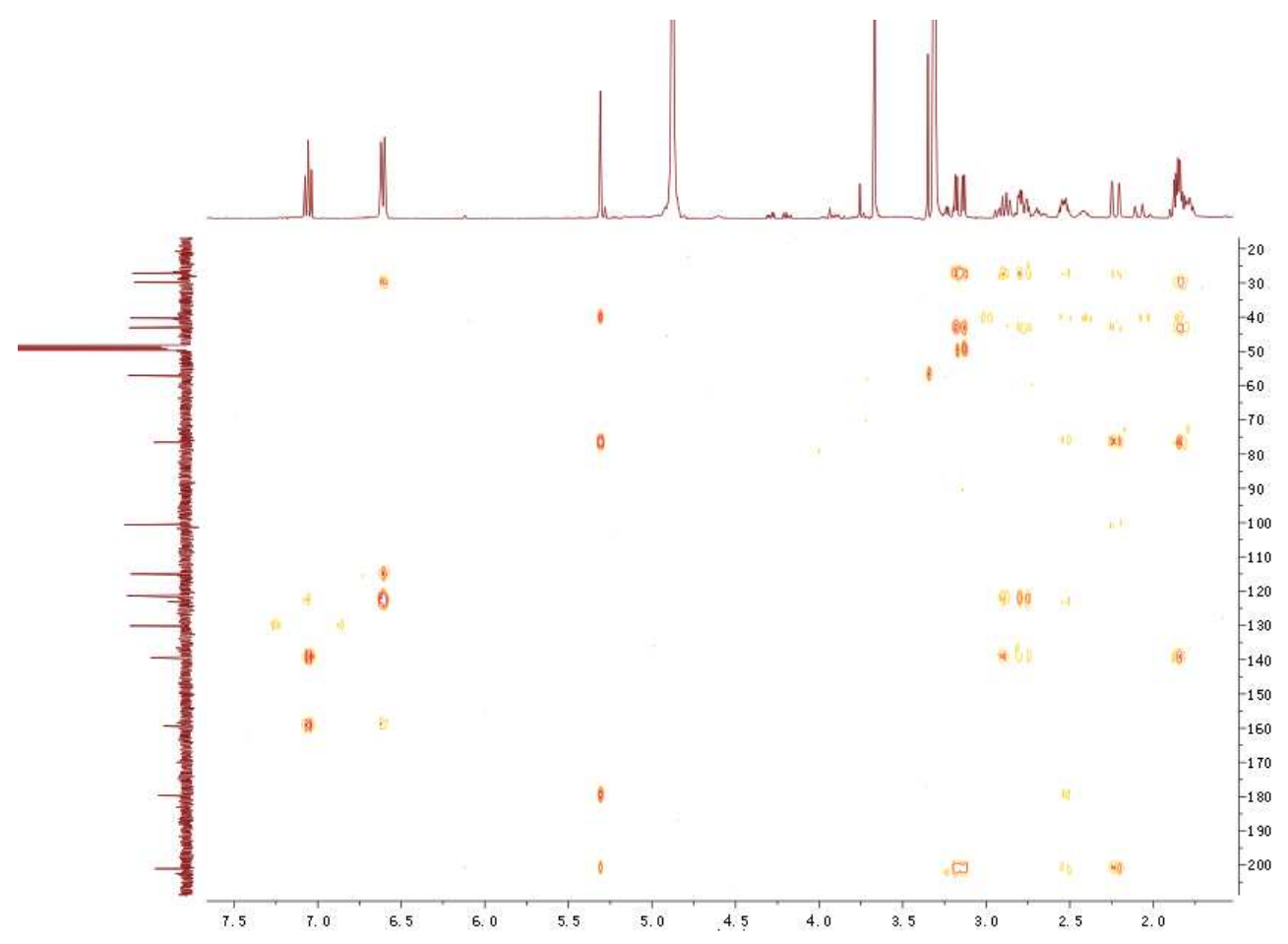

Figure S17. The ${ }^{1} \mathrm{H}-{ }^{1} \mathrm{H}$ COSY spectrum of compound 3 in MeOD

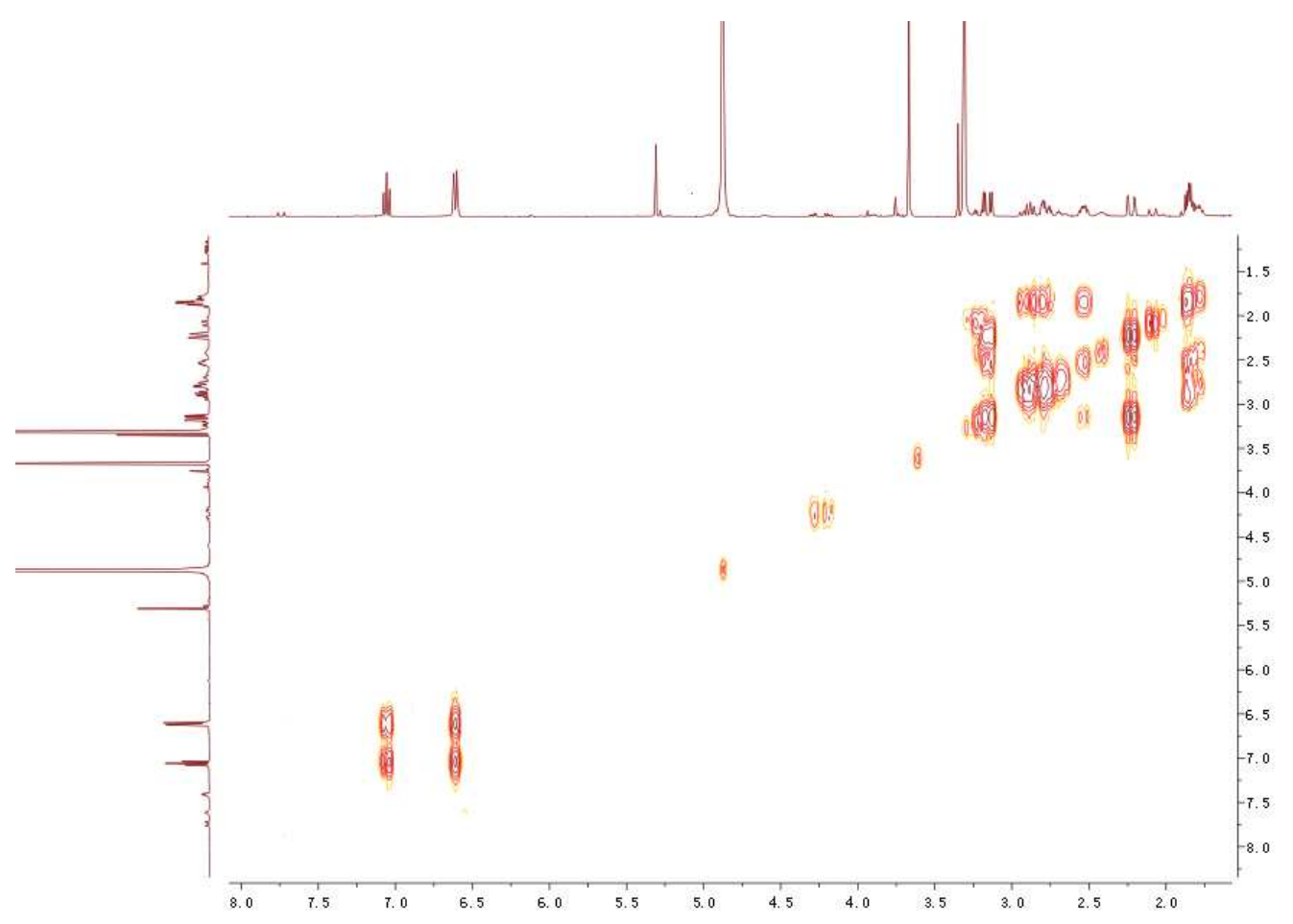


Figure S18. The HRESIMS of compound 3

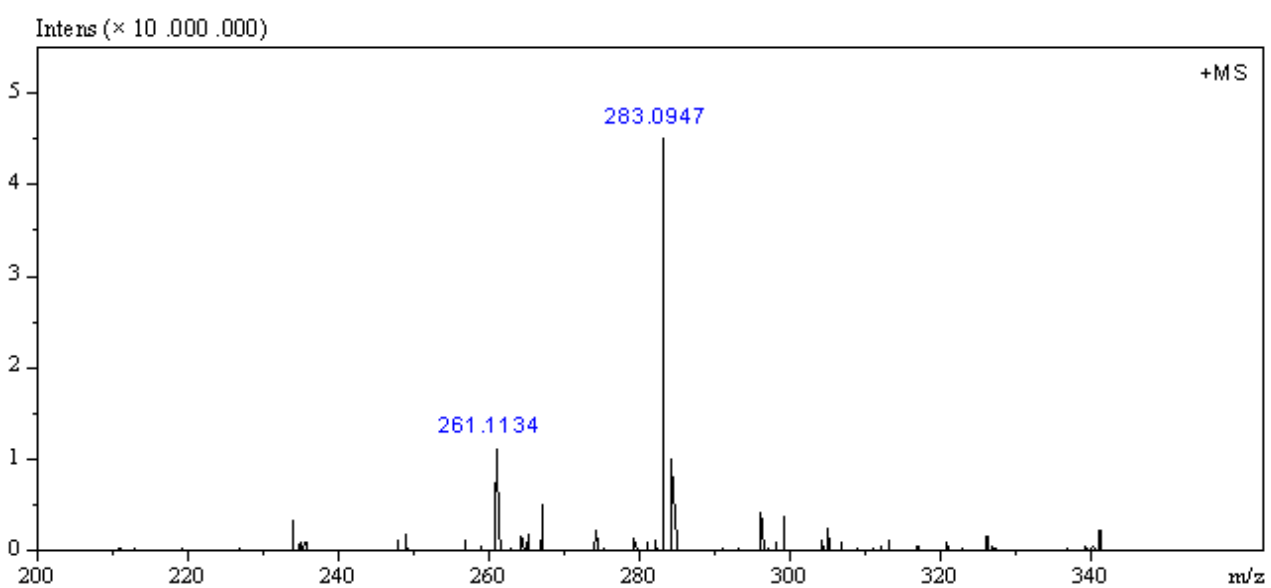


Figure S19. The ${ }^{1} \mathrm{H}-\mathrm{NMR}$ spectrum of compound $\mathbf{4}$ in MeOD

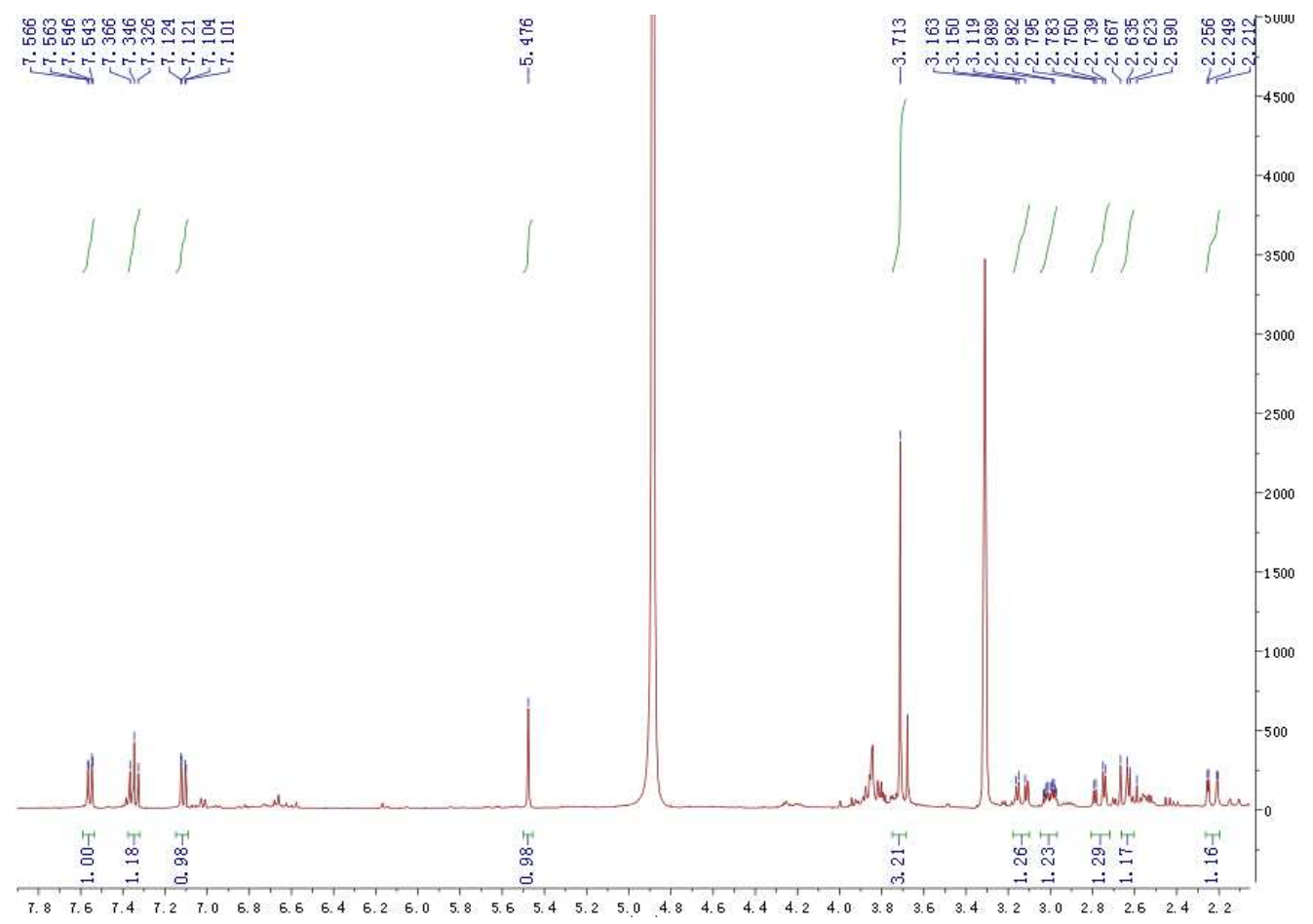

Figure S20. The ${ }^{13} \mathrm{C}-\mathrm{NMR}$ spectrum of compound $\mathbf{4}$ in MeOD

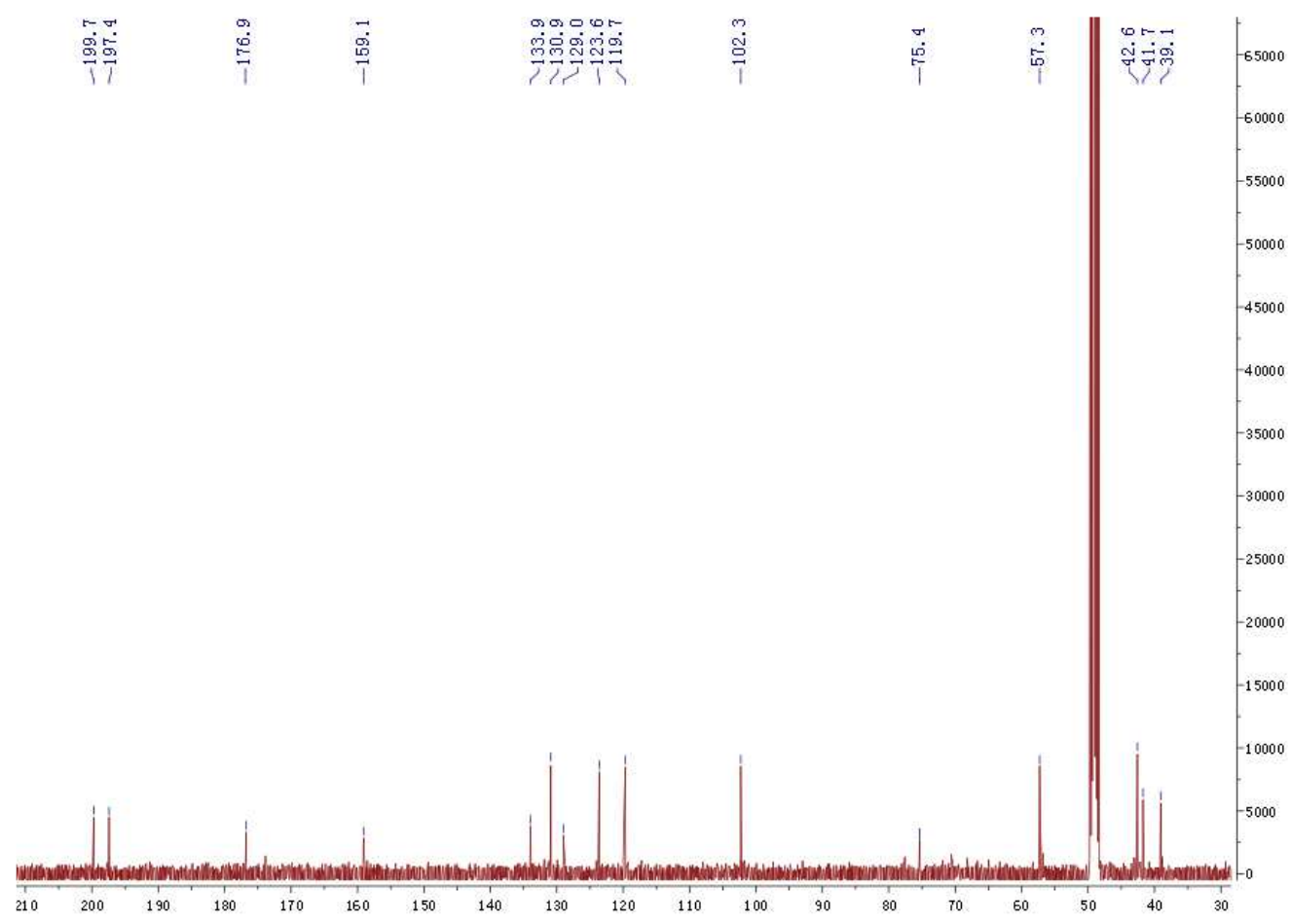


Figure S21. The DEPT spectrum of compound 4 in GeOD

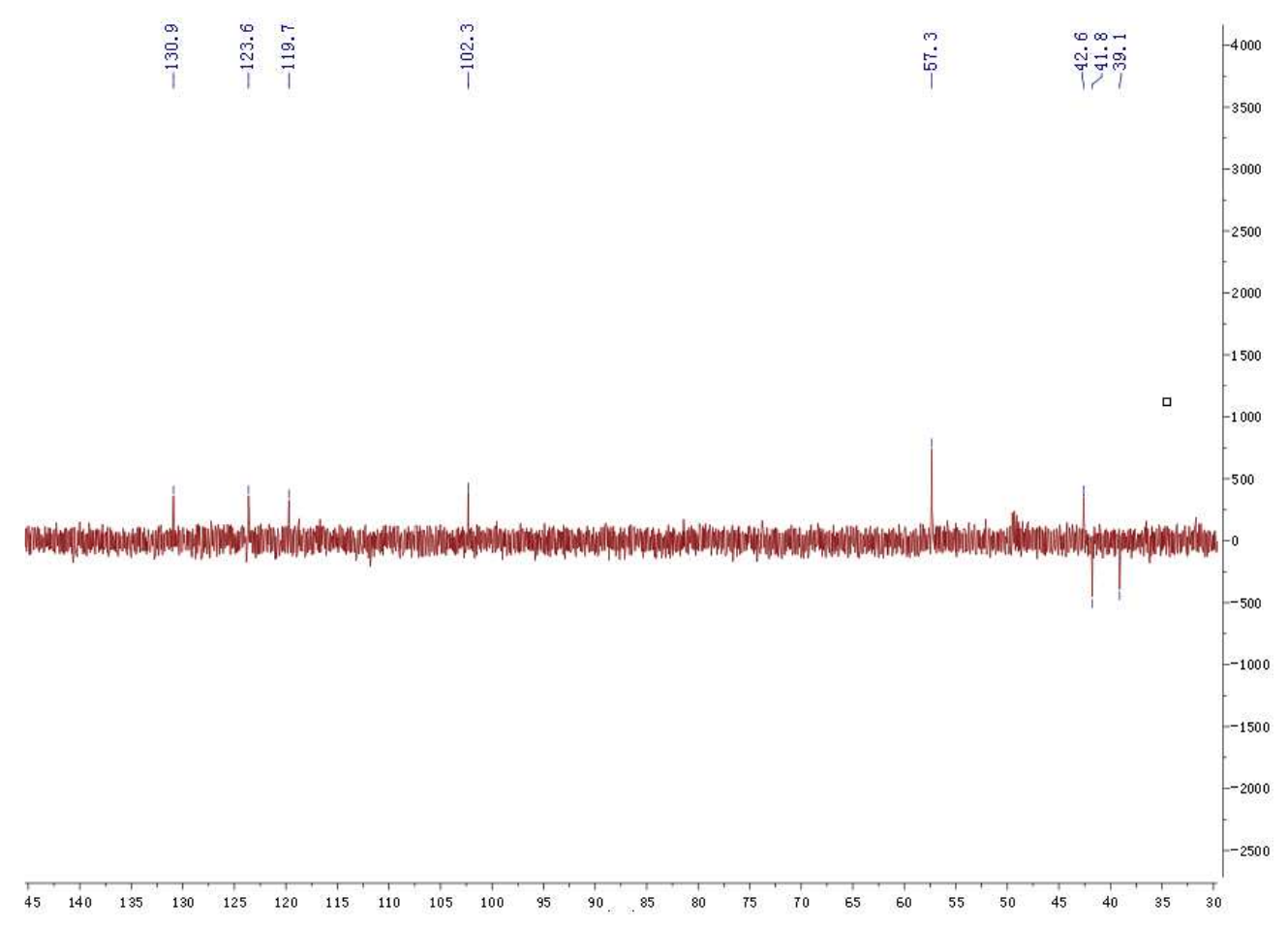

Figure S22. The HSQC spectrum of compound 4 in GeOD

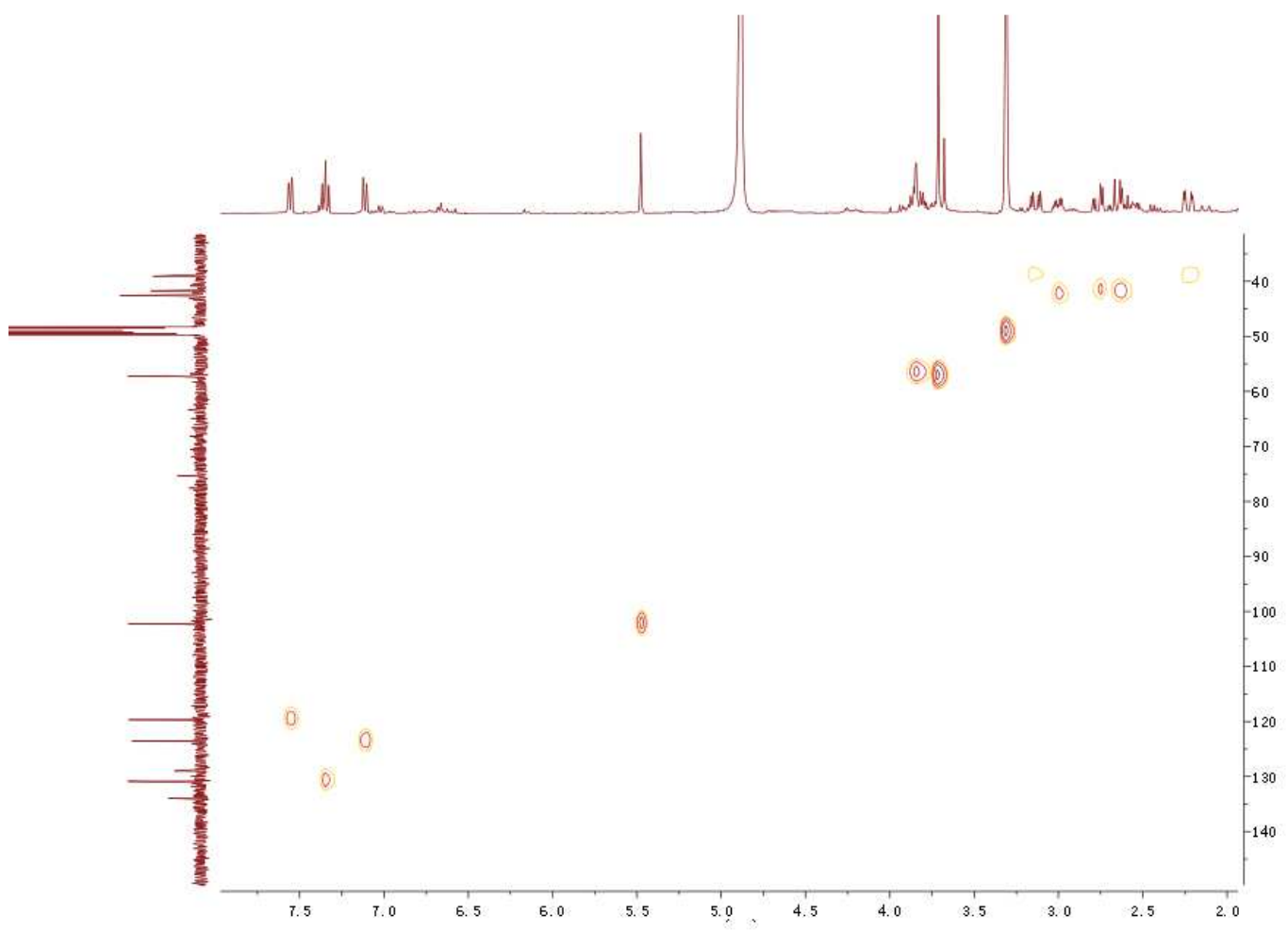


Figure S23. The HMBC spectrum of compound 4 in MeOD

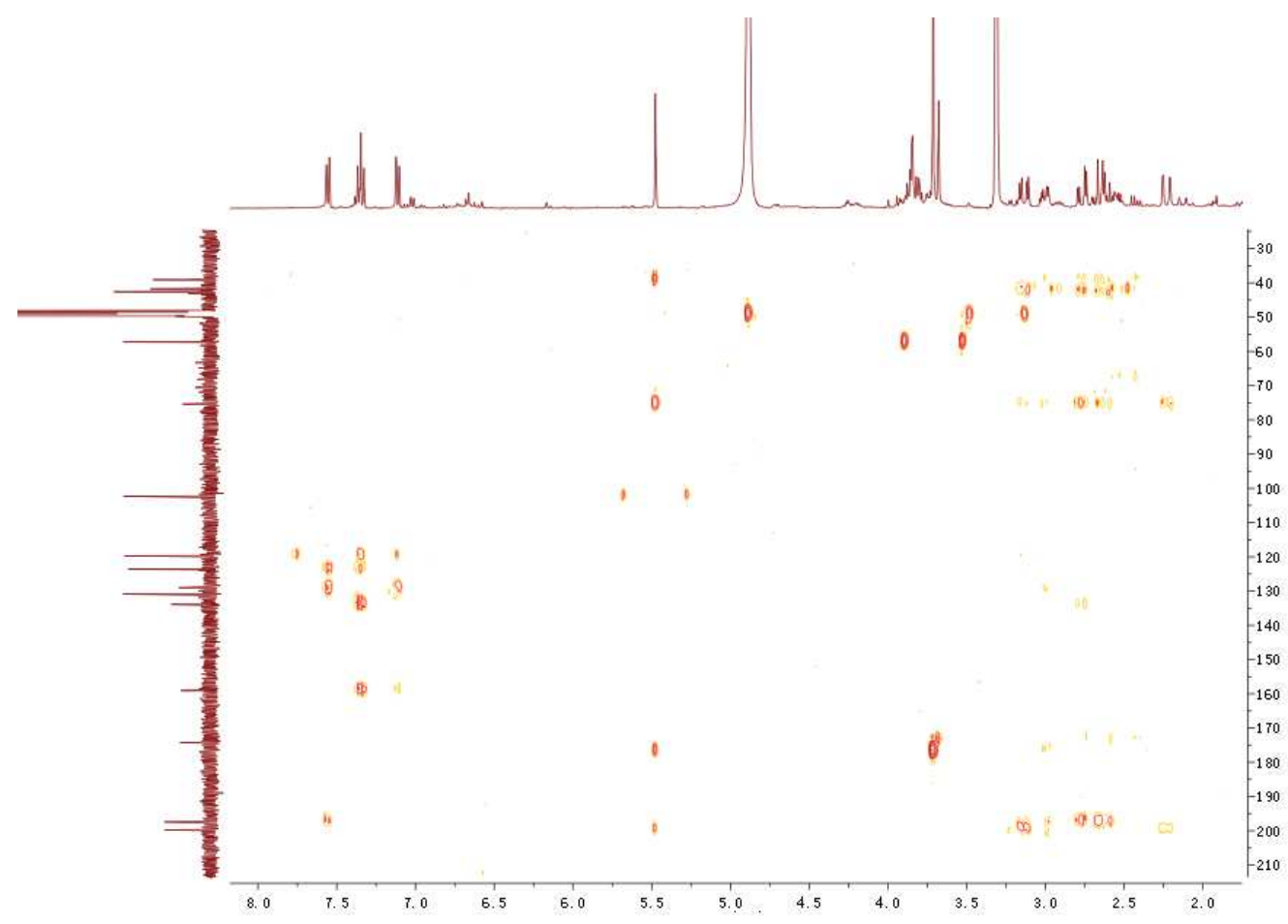

Figure S24. The ${ }^{1} \mathrm{H}-{ }^{1} \mathrm{H}$ COSY spectrum of compound 4 in MeOD

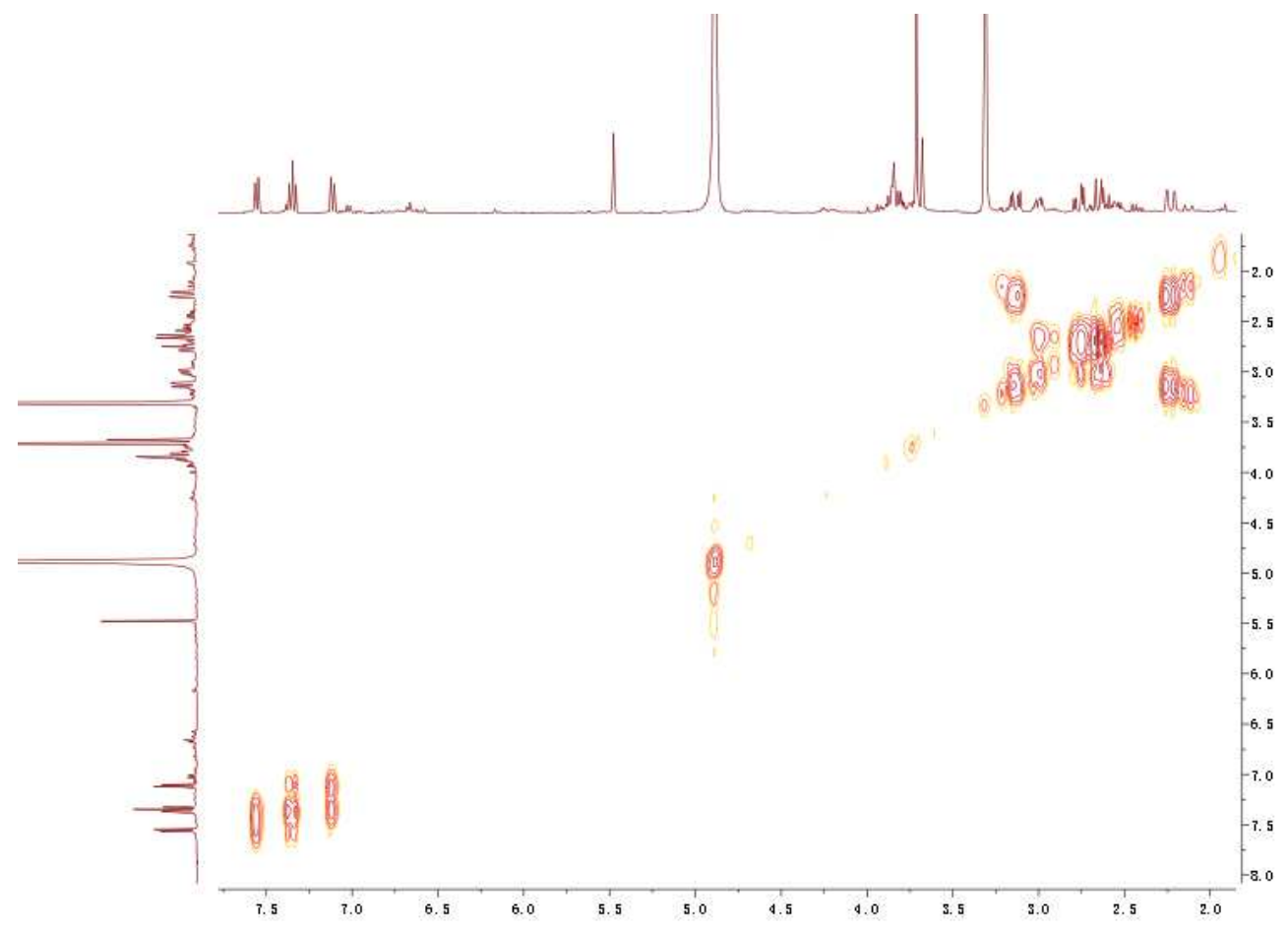


Figure S25. The HRESIMS of compound 4

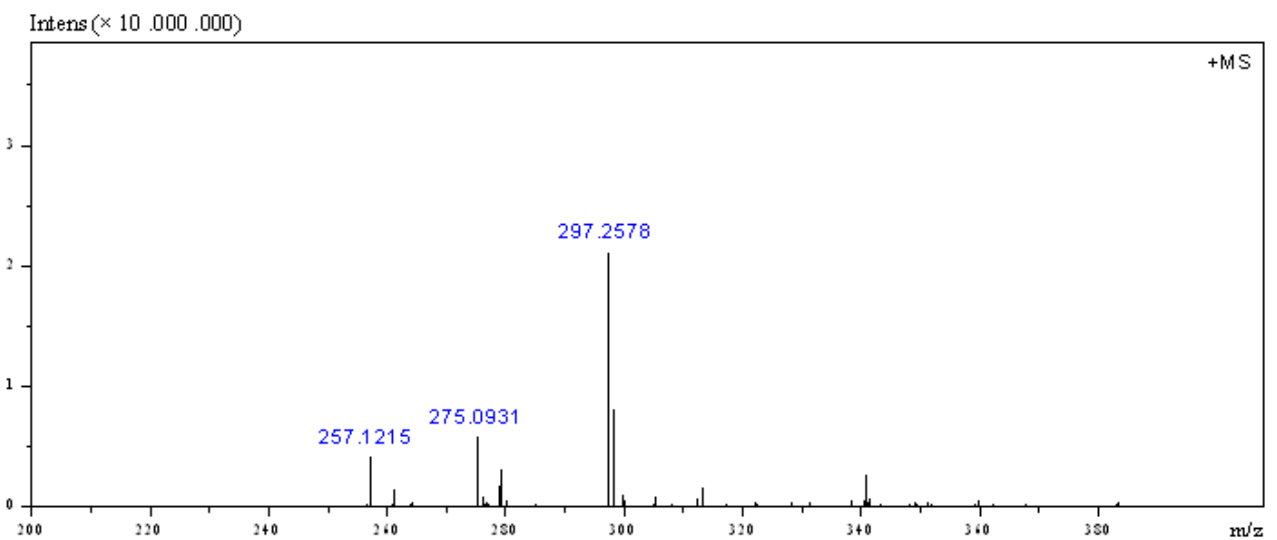


Figure S26. The ${ }^{1} \mathrm{H}-\mathrm{NMR}$ spectrum of compound 5 in acetone- $d_{6}$

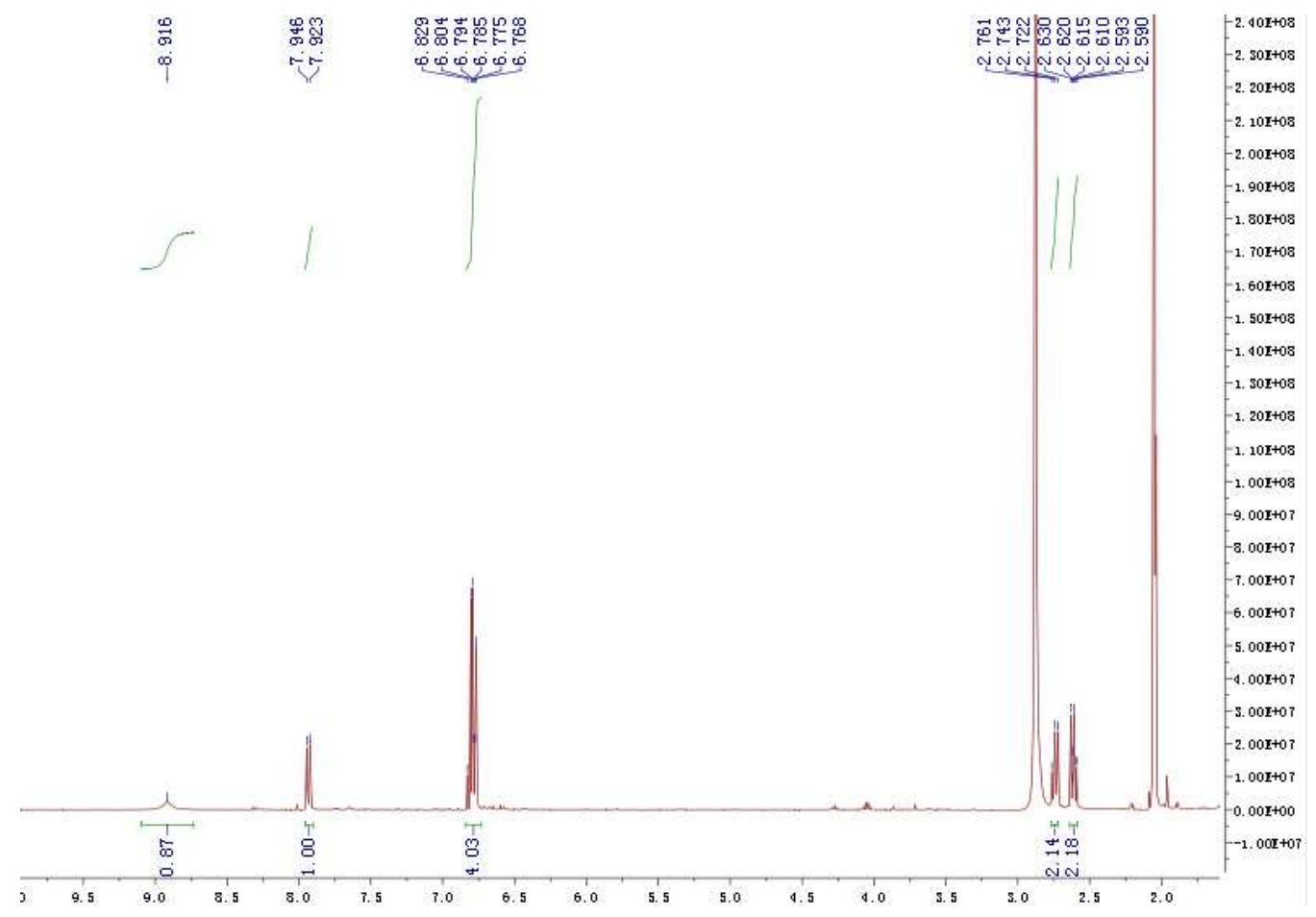

Figure S27. The ${ }^{13} \mathrm{C}$-NMR spectrum of compound 5 in acetone- $d_{6}$

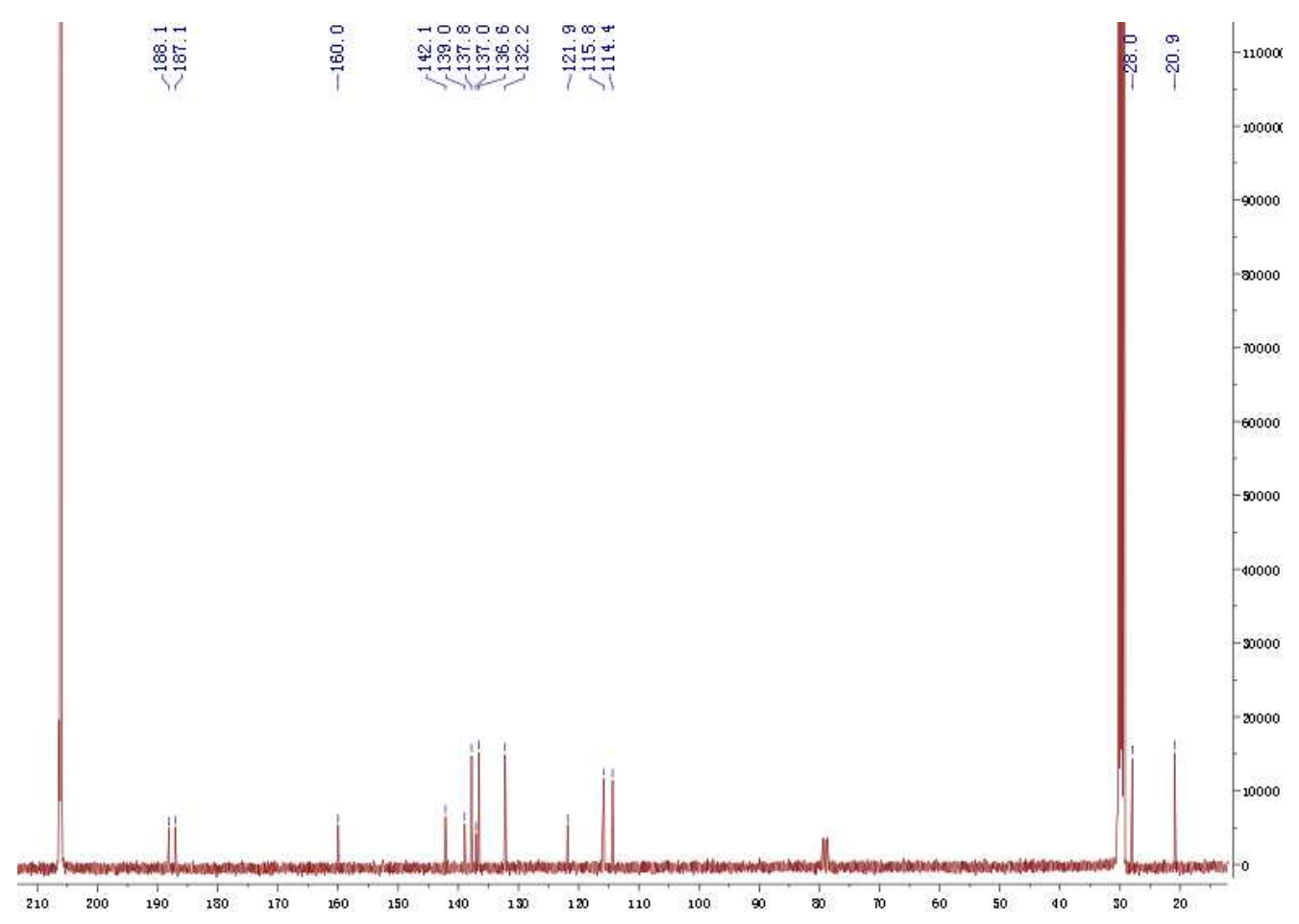


Figure S28. The HSQC spectrum of compound 5 in acetone- $d_{6}$

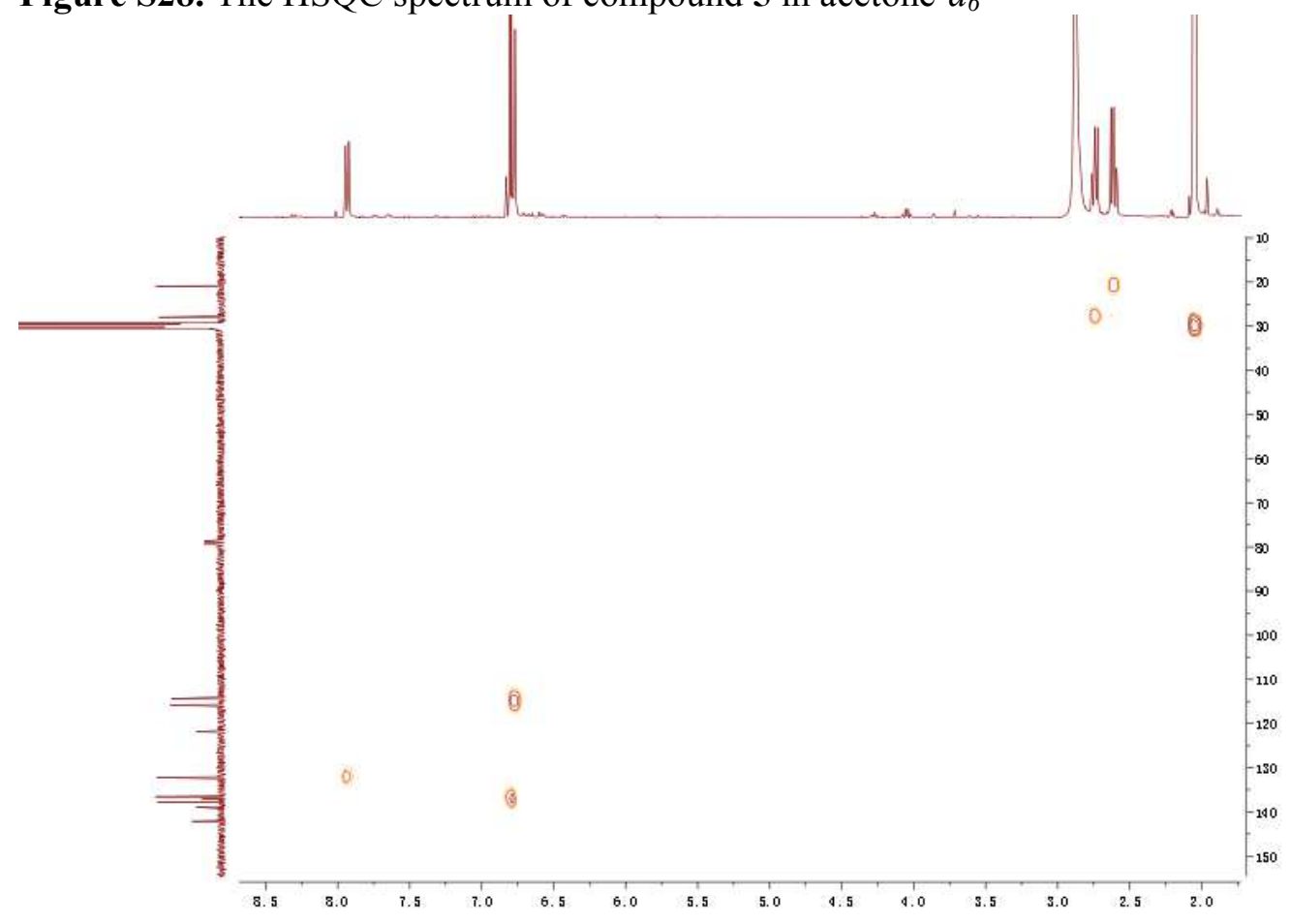

Figure S29. The HMBC spectrum of compound 5 in acetone- $d_{6}$

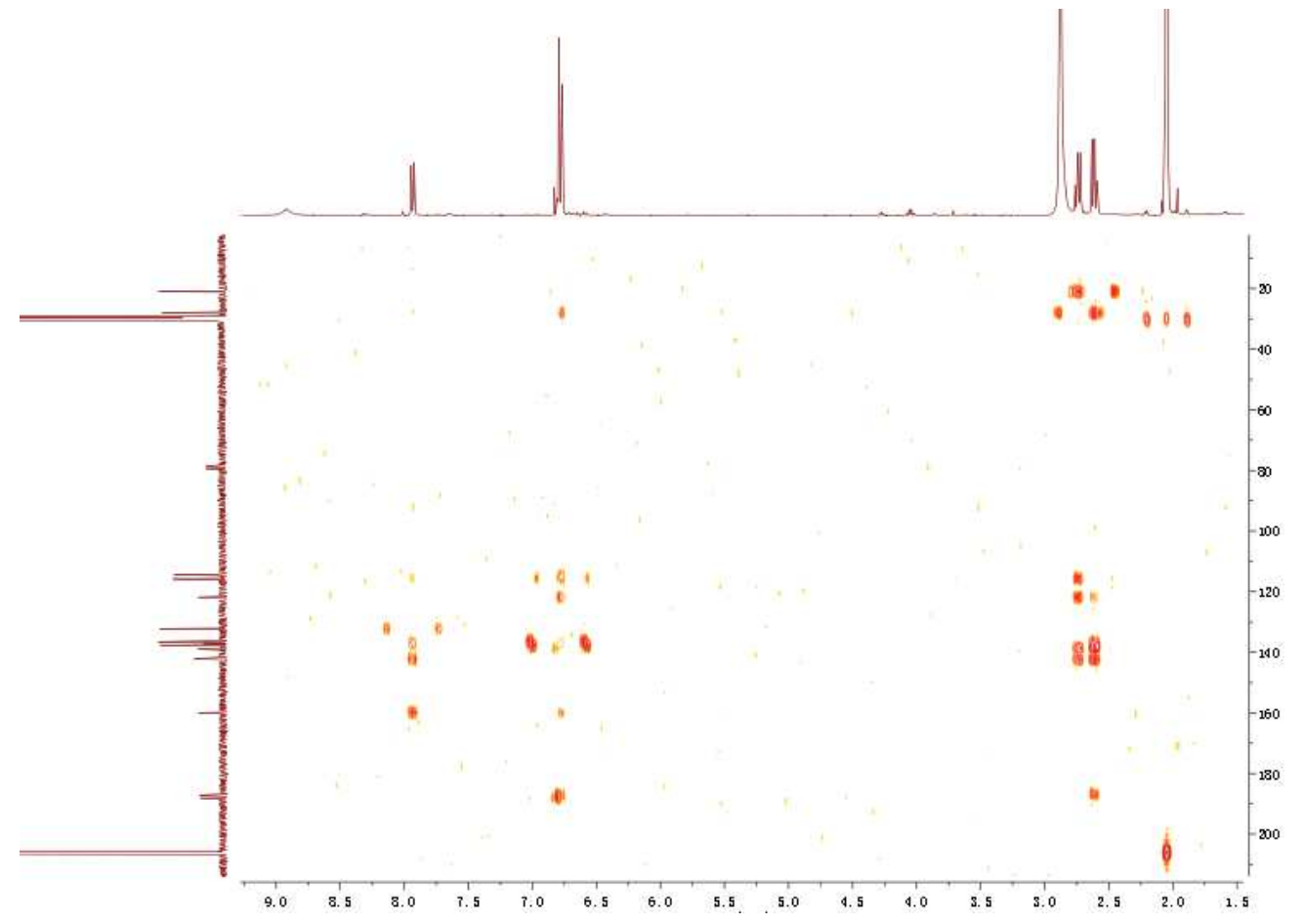


Figure S30. The ${ }^{1} \mathrm{H}-{ }^{1} \mathrm{H}$ COSY spectrum of compound 5 in acetone- $d_{6}$

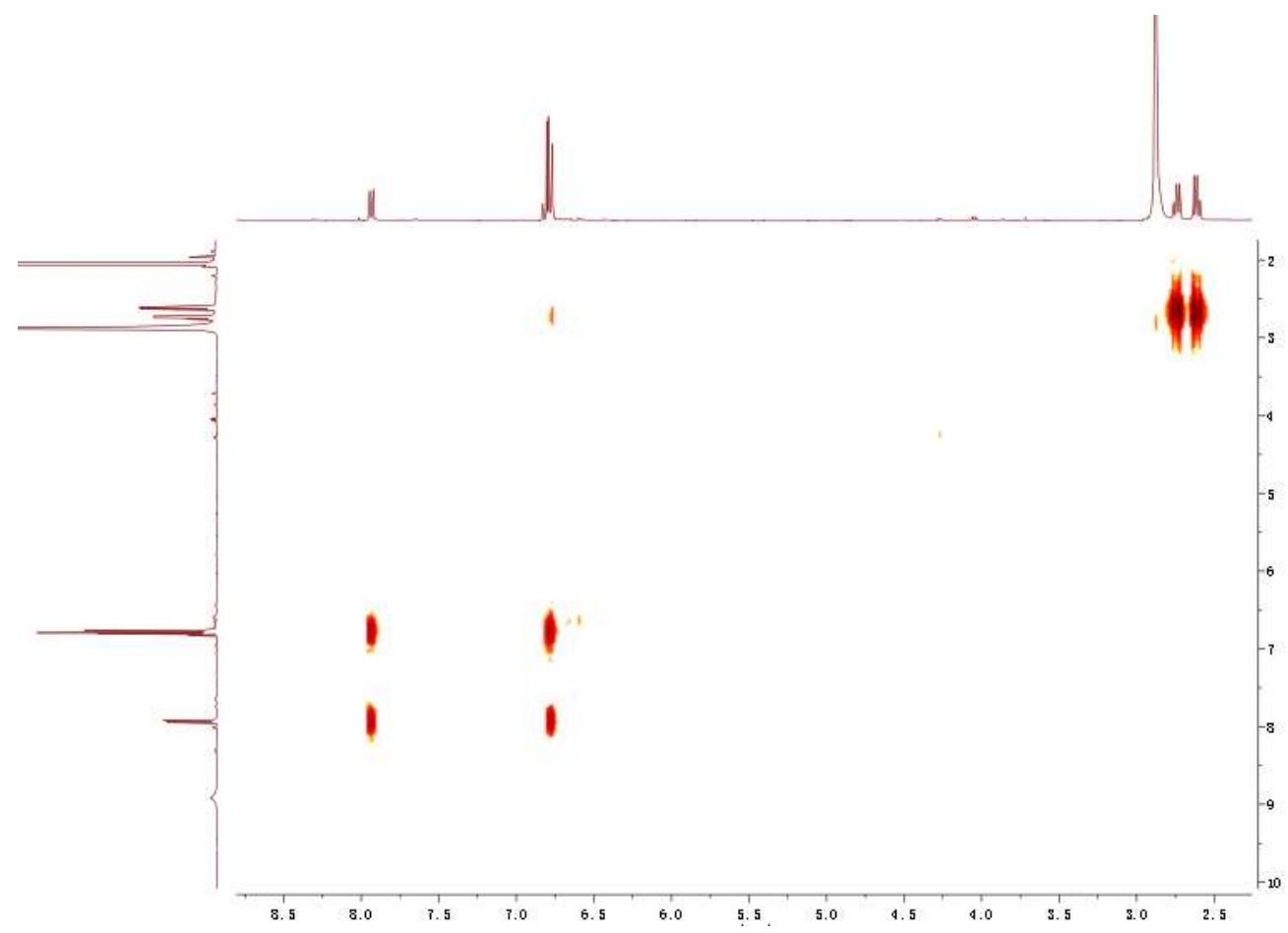

Figure S31. The HRESIMS of compound 5

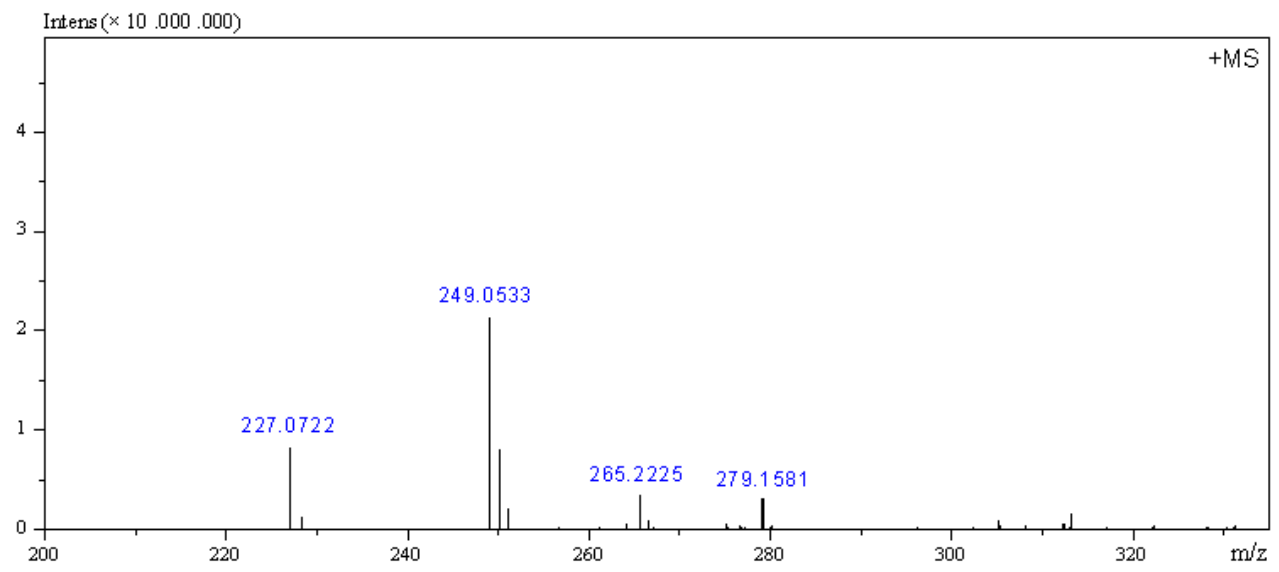


Figure S32. The ${ }^{1}$ H-NMR spectrum of compound 22 in Acetone- $d_{6}$

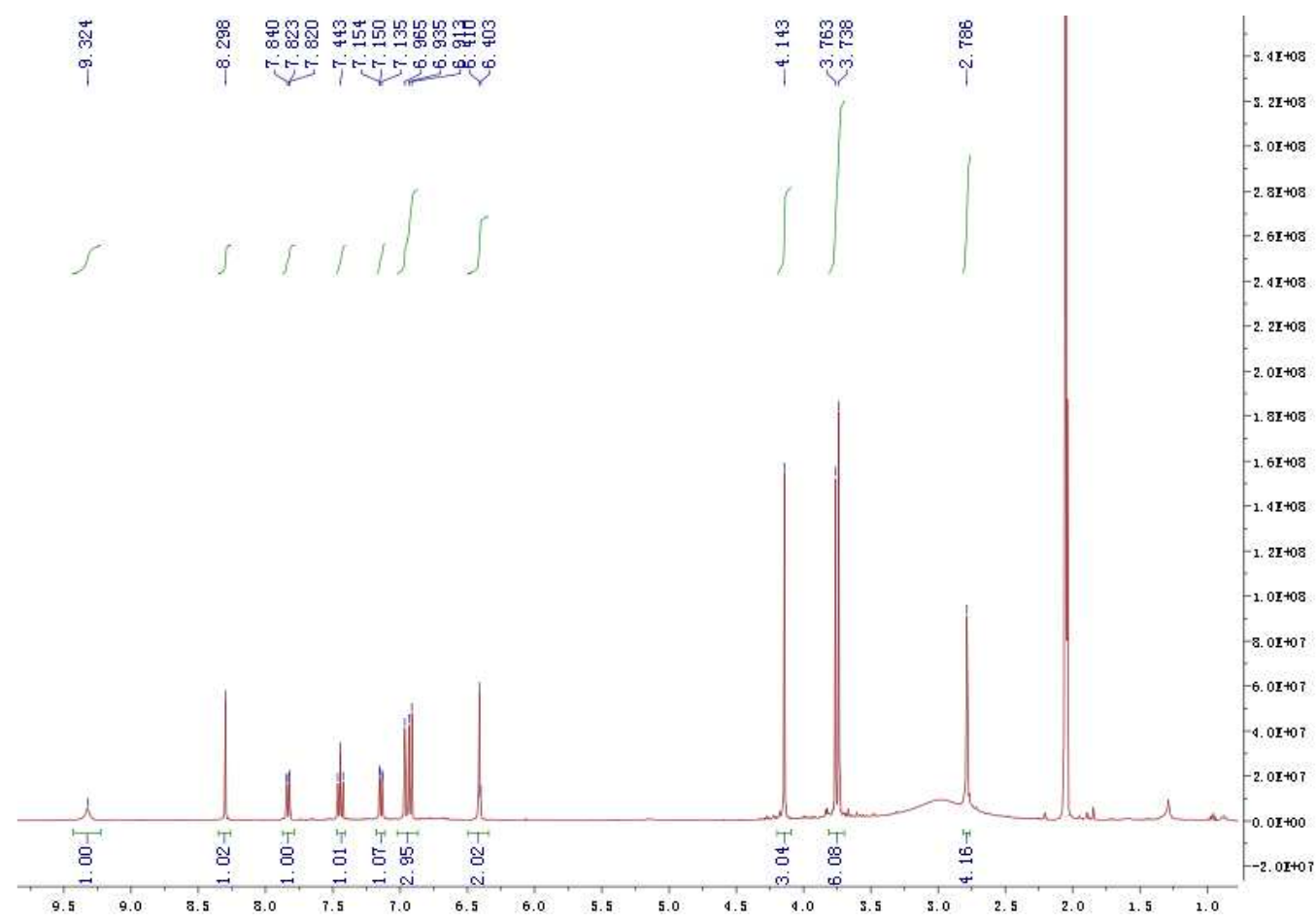

Figure S33. The ${ }^{13} \mathrm{C}-\mathrm{NMR}$ spectrum of compound 22 in Acetone- $d_{6}$

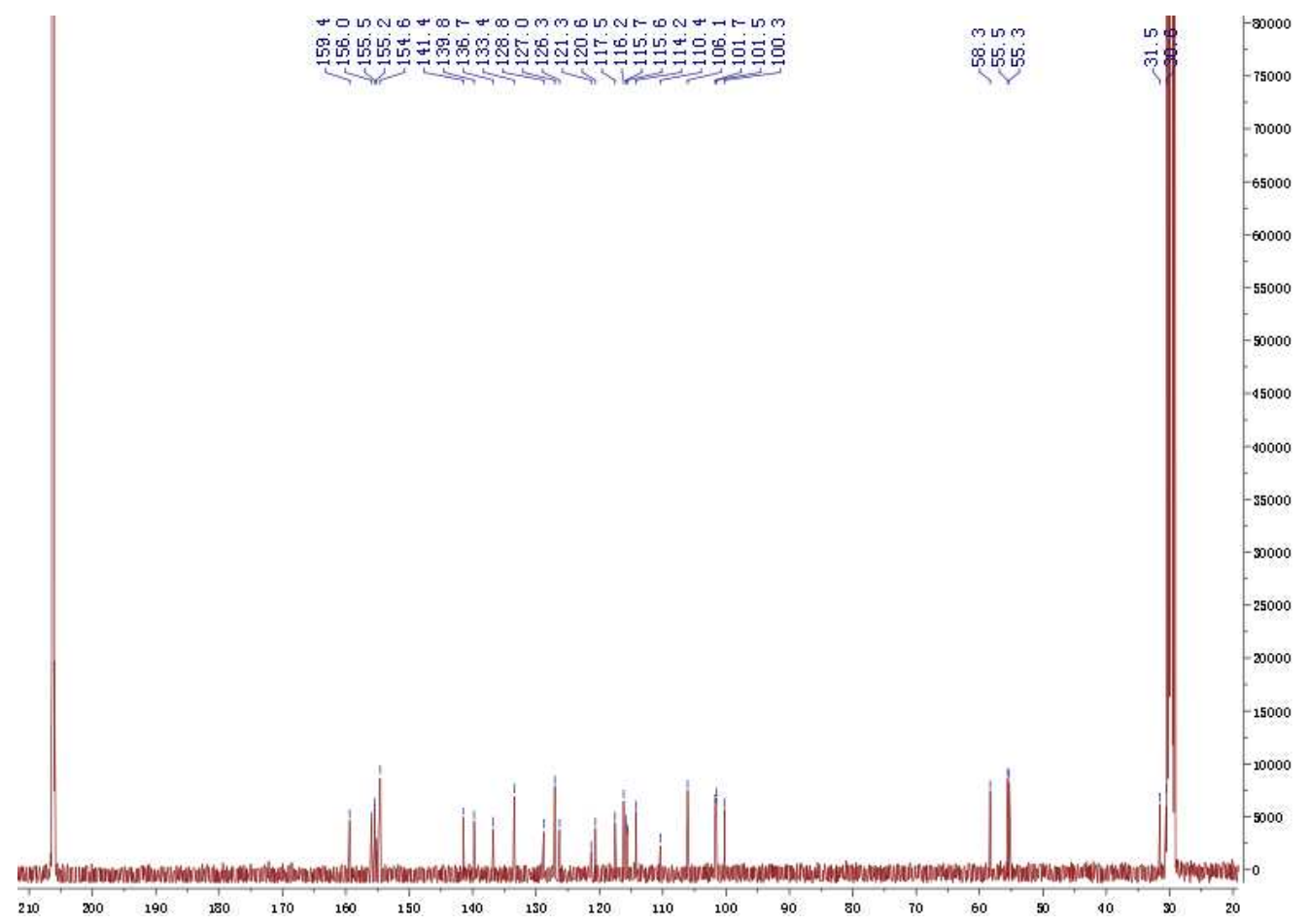


Figure S34. The DEPT spectrum of compound 22 in Acetone- $d_{6}$

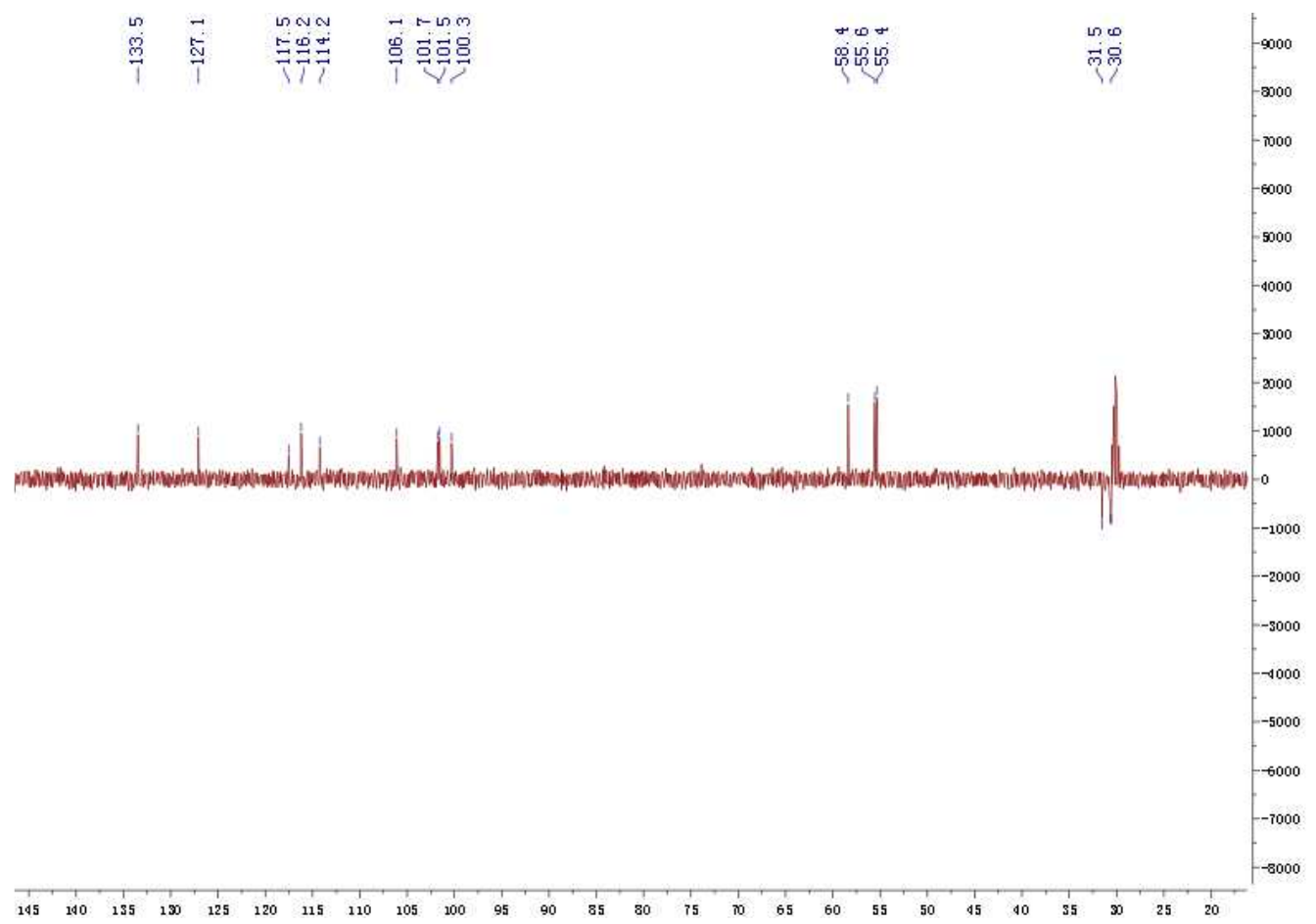

Figure S35. The HSQC spectrum of compound 22 in Acetone- $d_{6}$

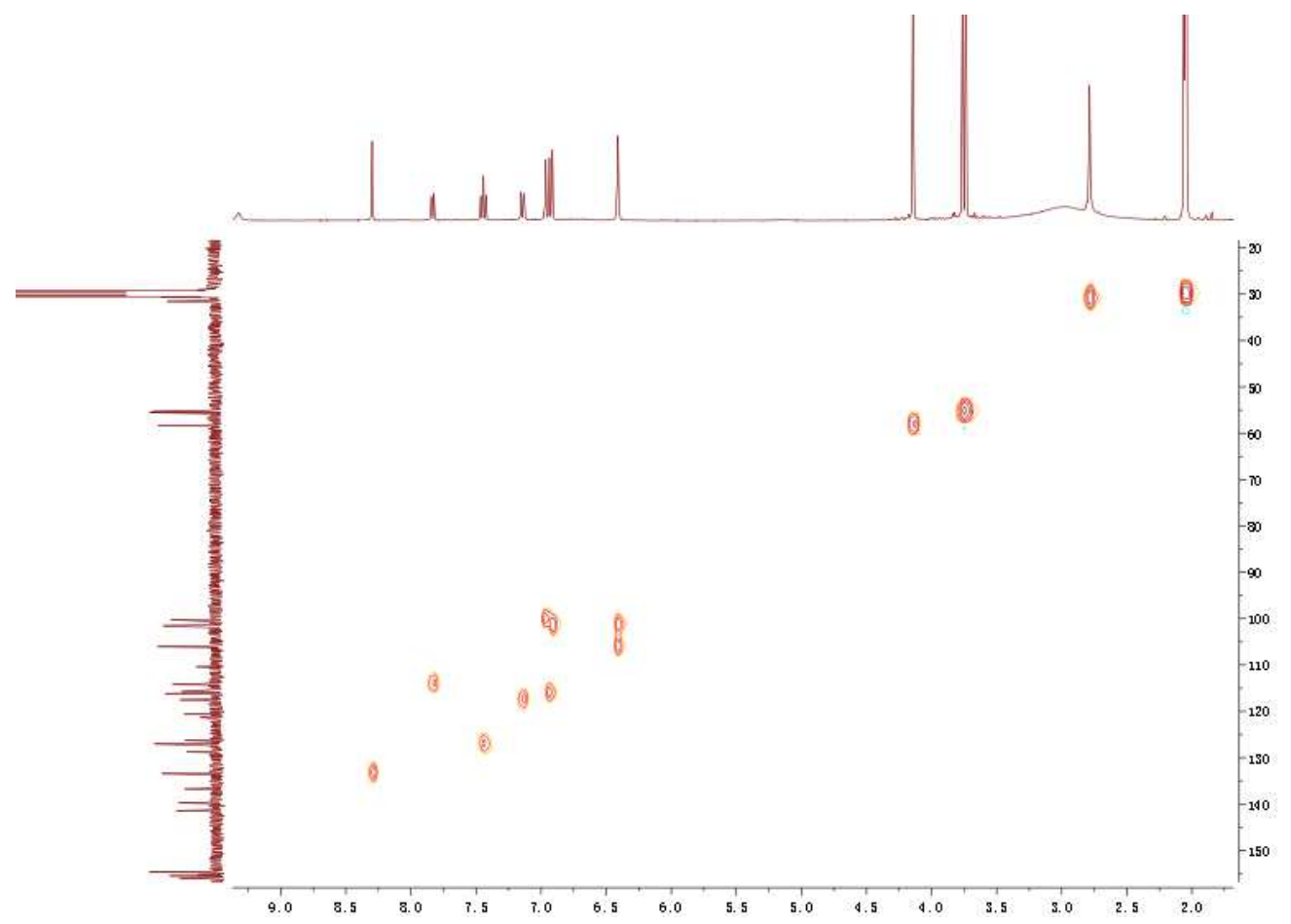


Figure S36. The HMBC spectrum of compound 22 in Acetone- $d_{6}$

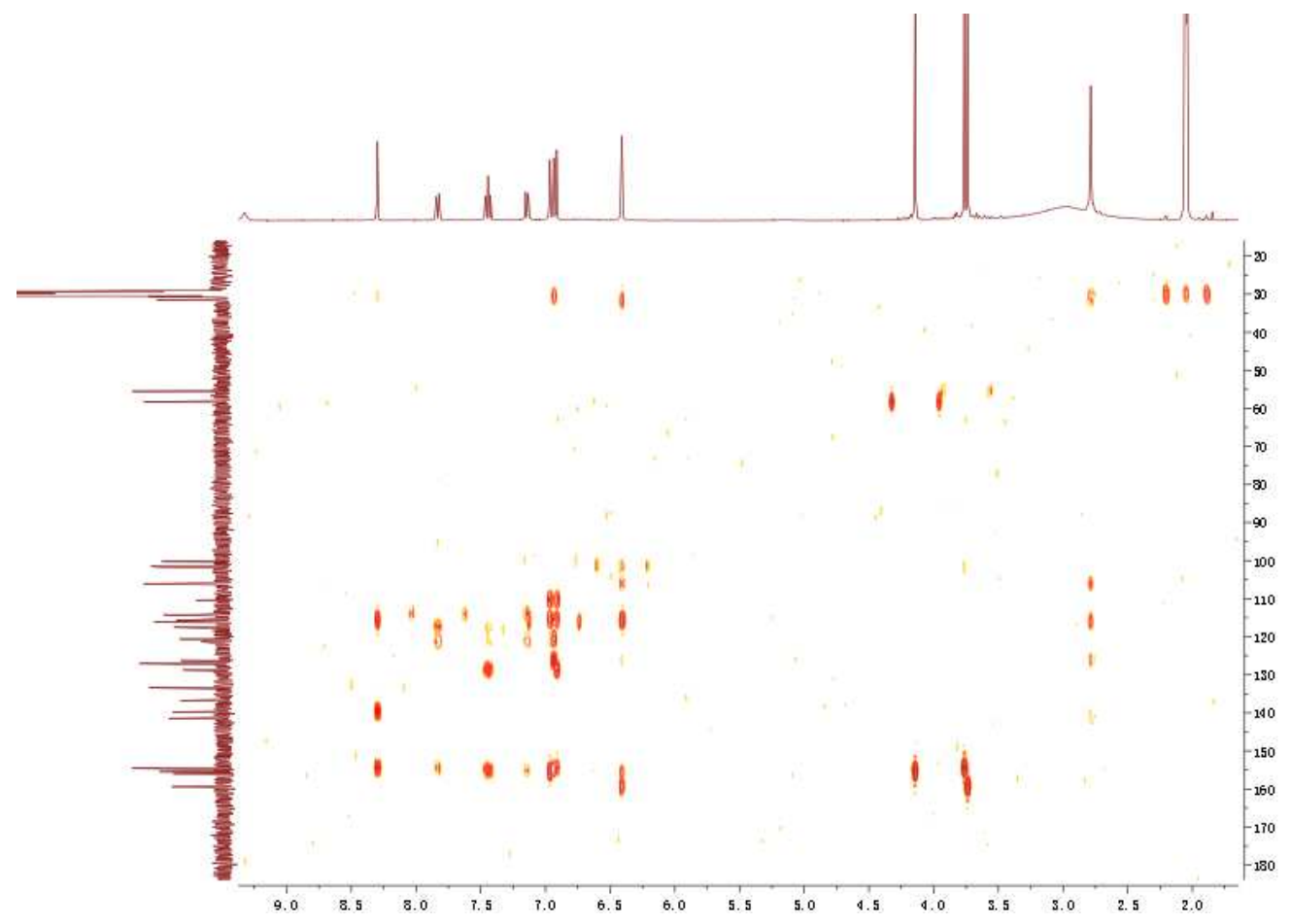

Figure S37. The ${ }^{1} \mathrm{H}-{ }^{1} \mathrm{H}$ COSY spectrum of compound 22 in Acetone- $d_{6}$

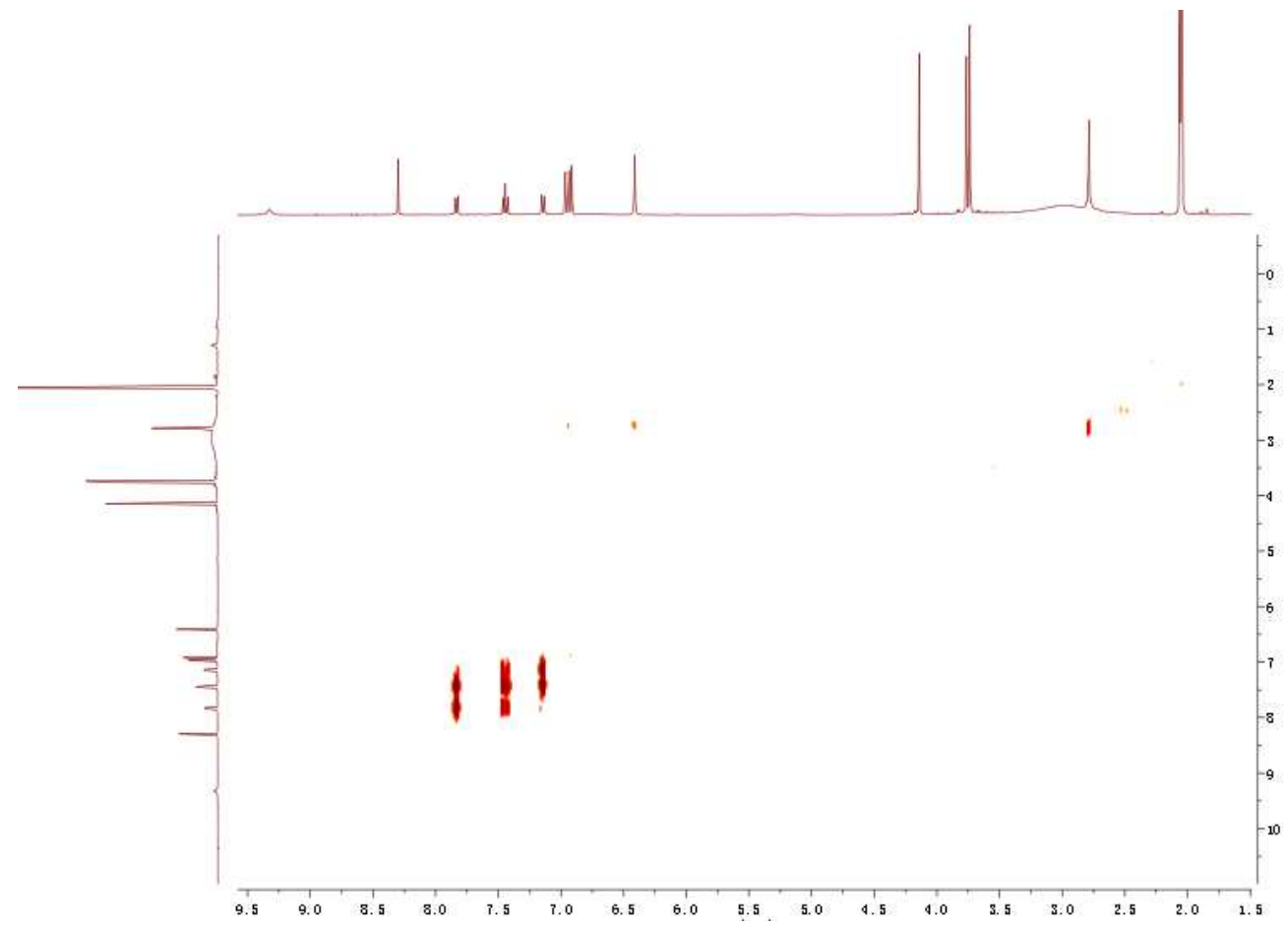


Figure S38. The HRESIMS of compound 22

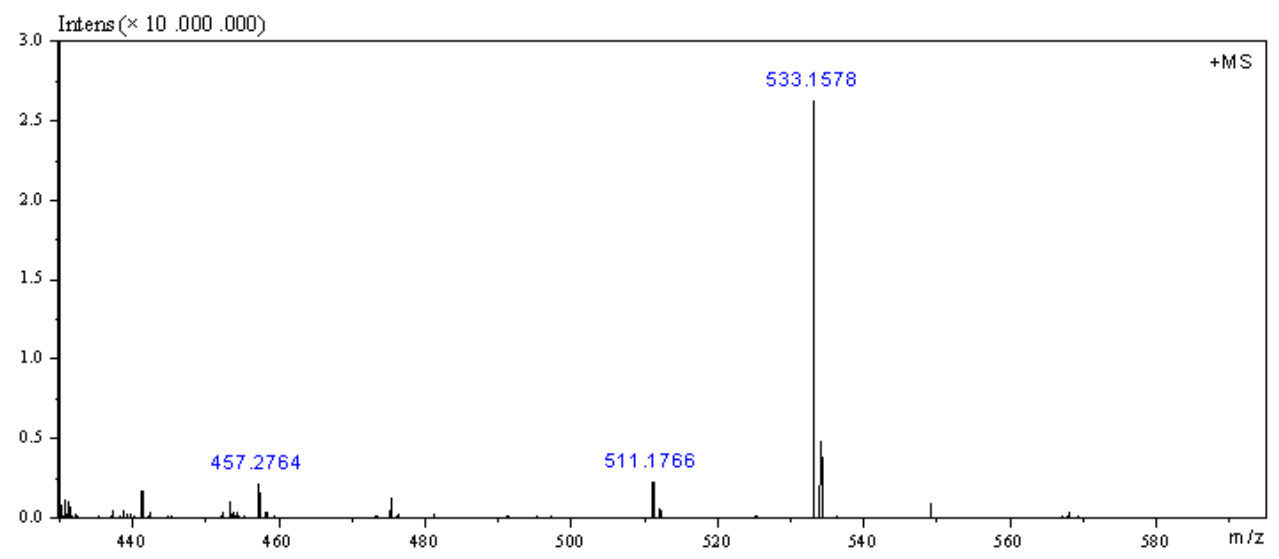


Figure S42. The ${ }^{1} \mathrm{H}-\mathrm{NMR}$ spectrum of compound $\mathbf{2 3}$ in Acetone- $d_{6}$

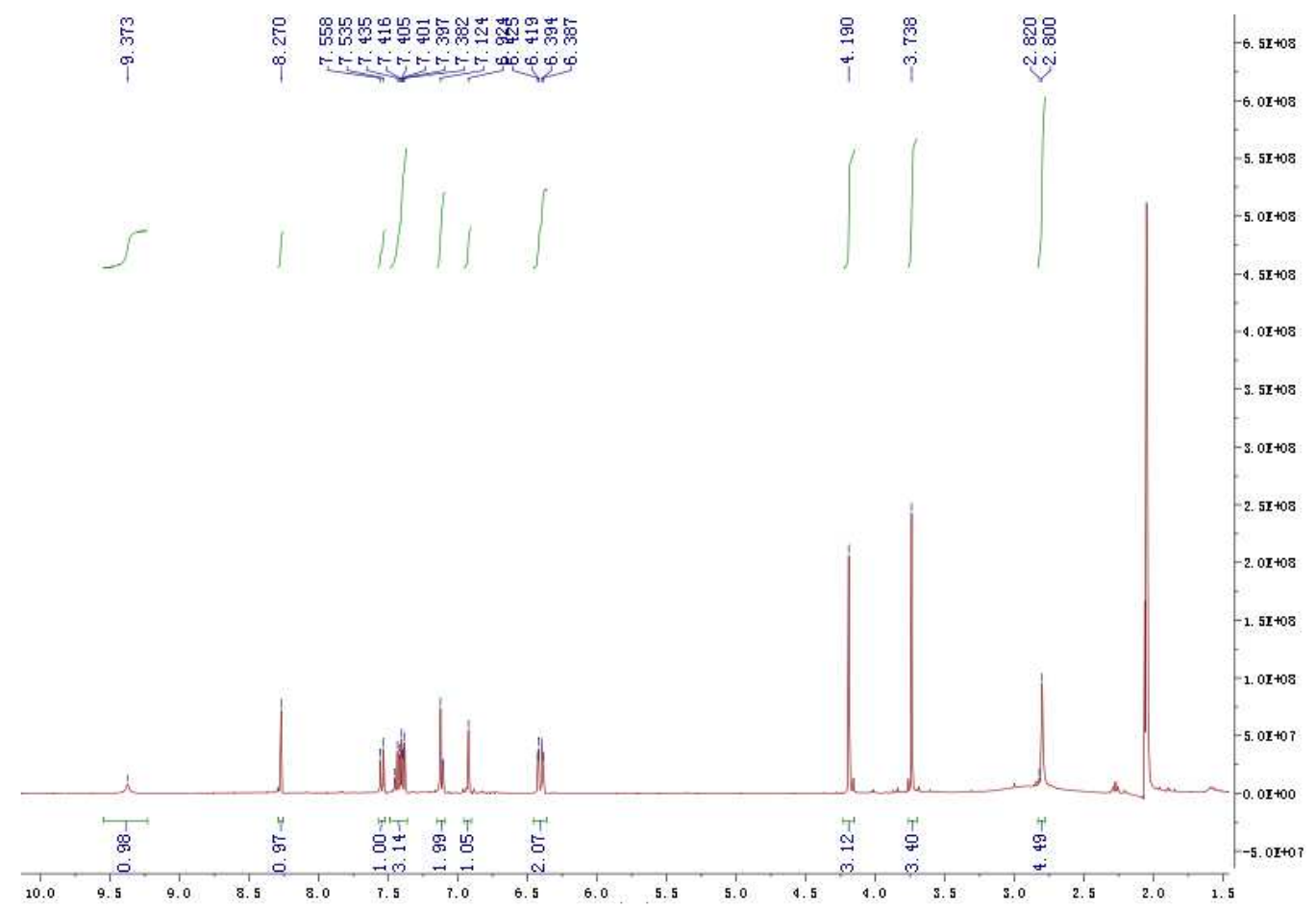

Figure S43. The ${ }^{13} \mathrm{C}-\mathrm{NMR}$ spectrum of compound 23 in Acetone- $d_{6}$

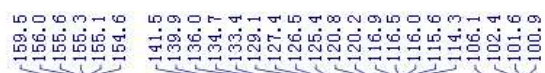

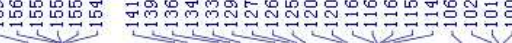

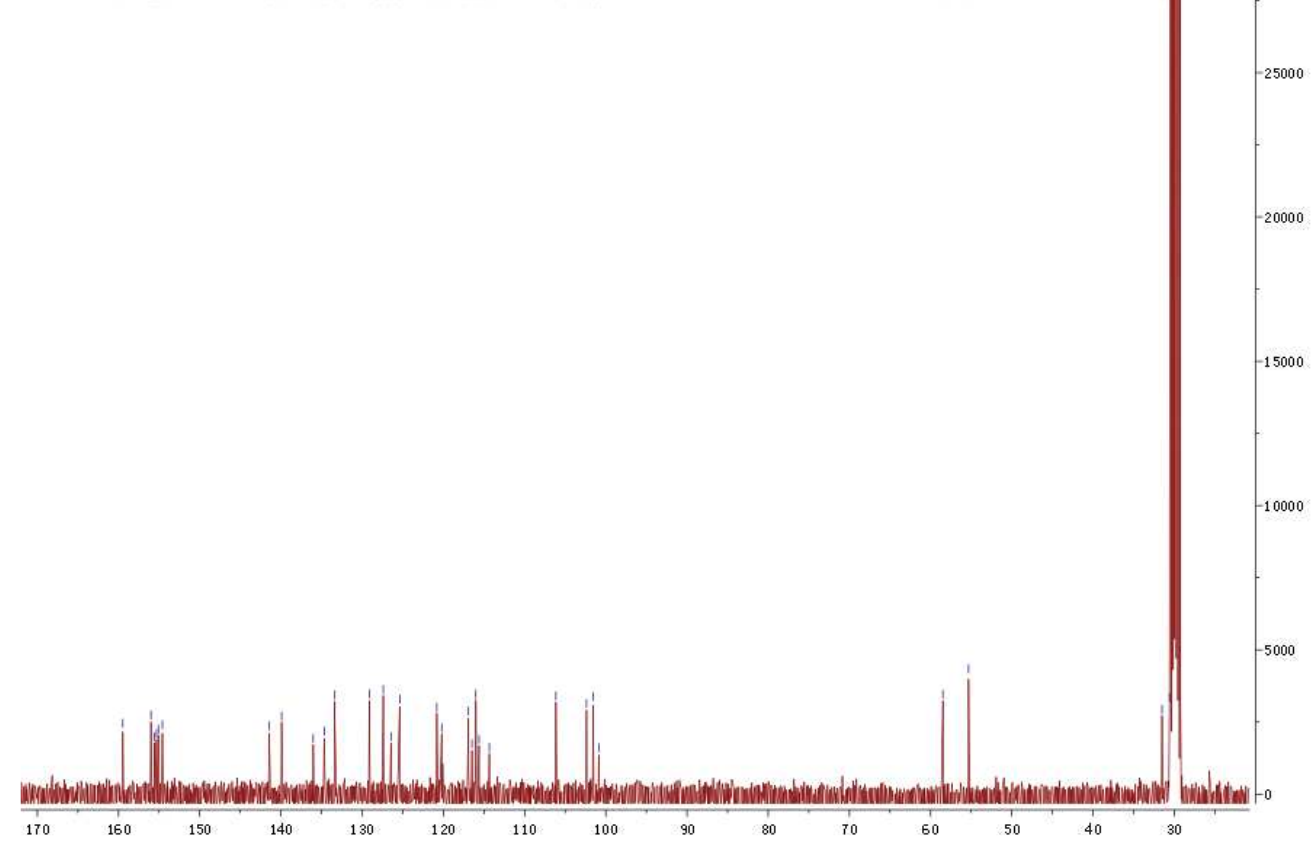

Figure S44. The DEPT spectrum of compound 23 in Acetone- $d_{6}$ 


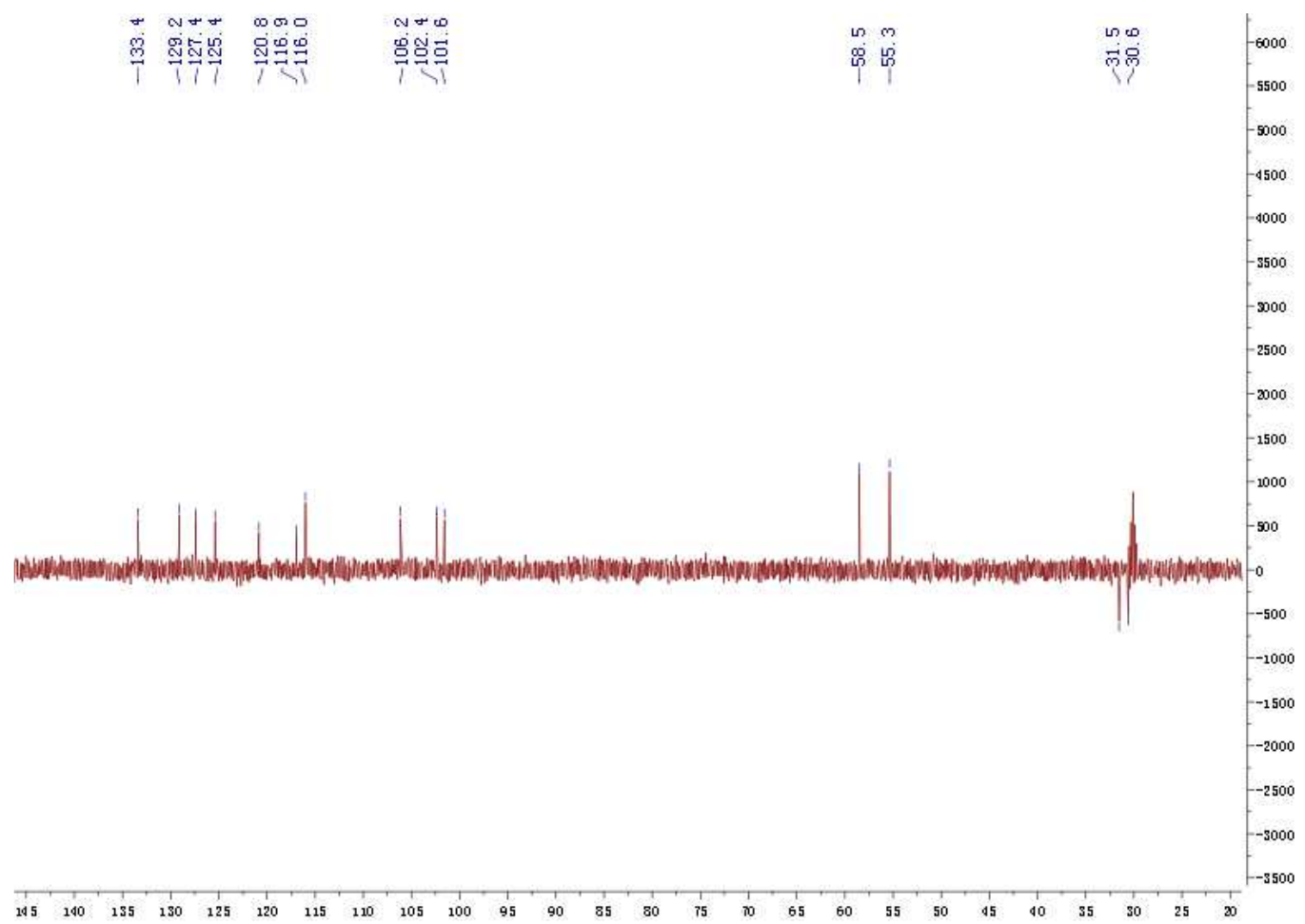

Figure S45. The HSQC spectrum of compound 23 in Acetone- $d_{6}$

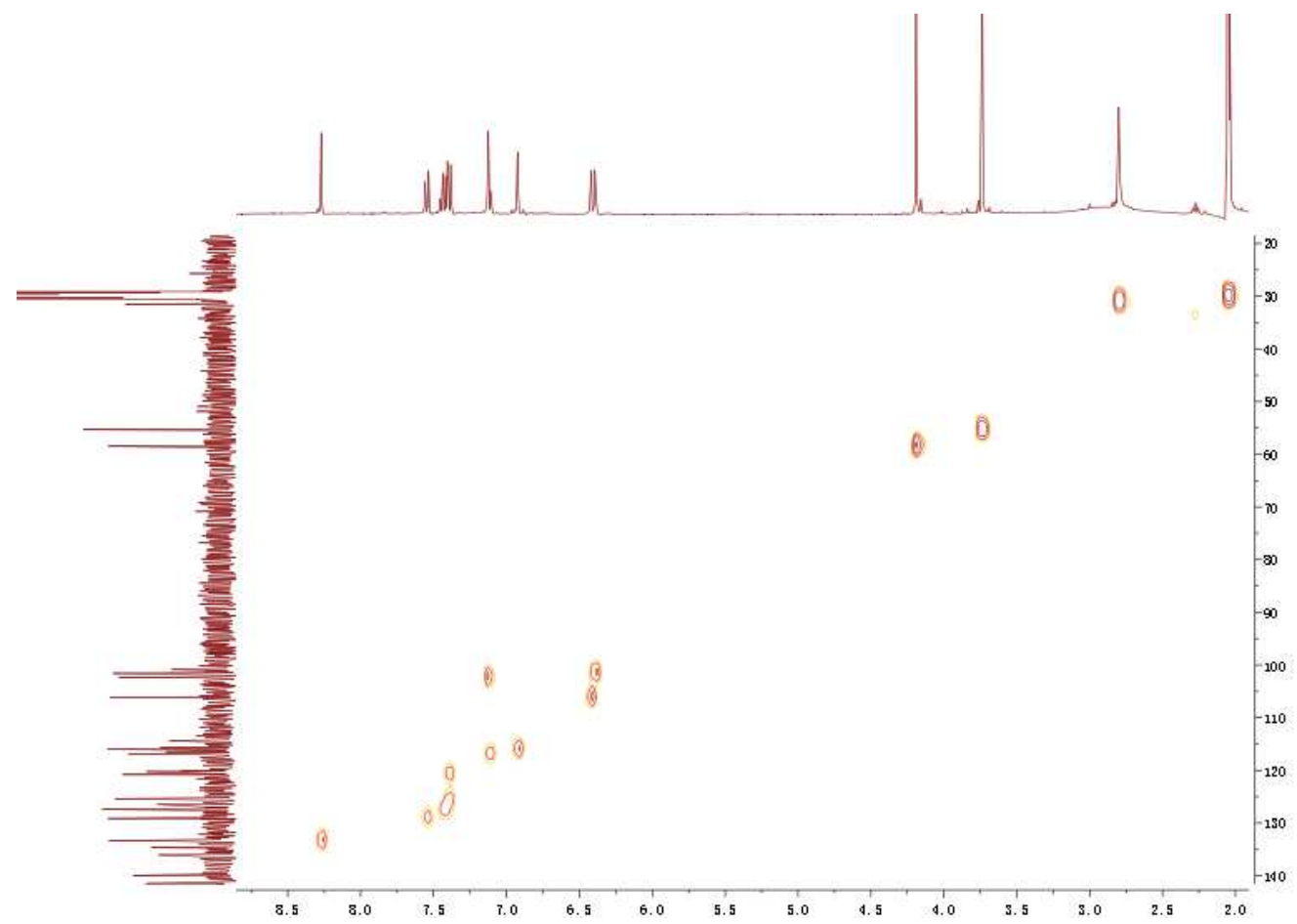

Figure S46. The HMBC spectrum of compound 23 in Acetone- $d_{6}$ 


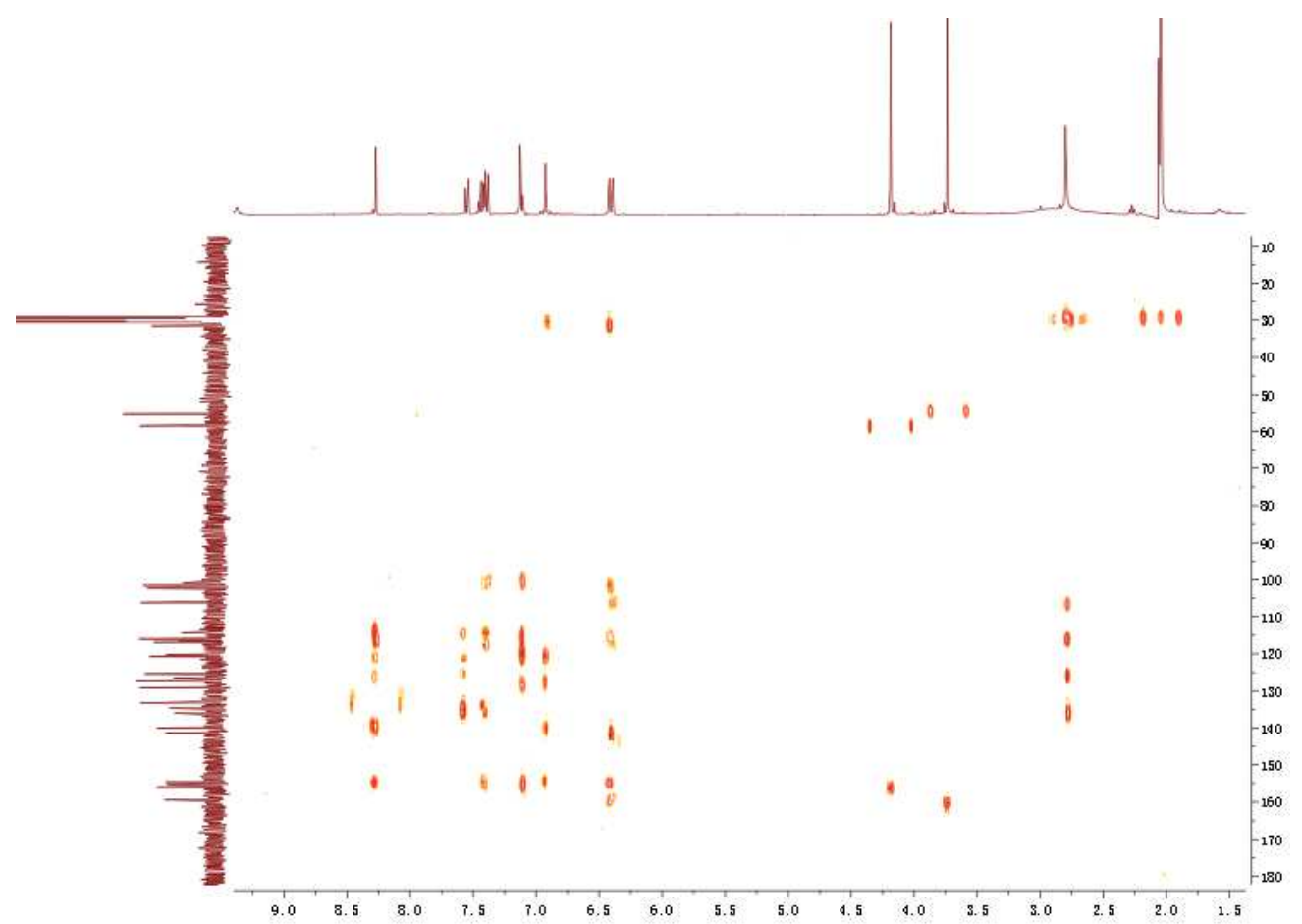

Figure S47. The ${ }^{1} \mathrm{H}-{ }_{-1} \mathrm{H}$ COSY spectrum of compound 23 in Acetone- $d_{6}$

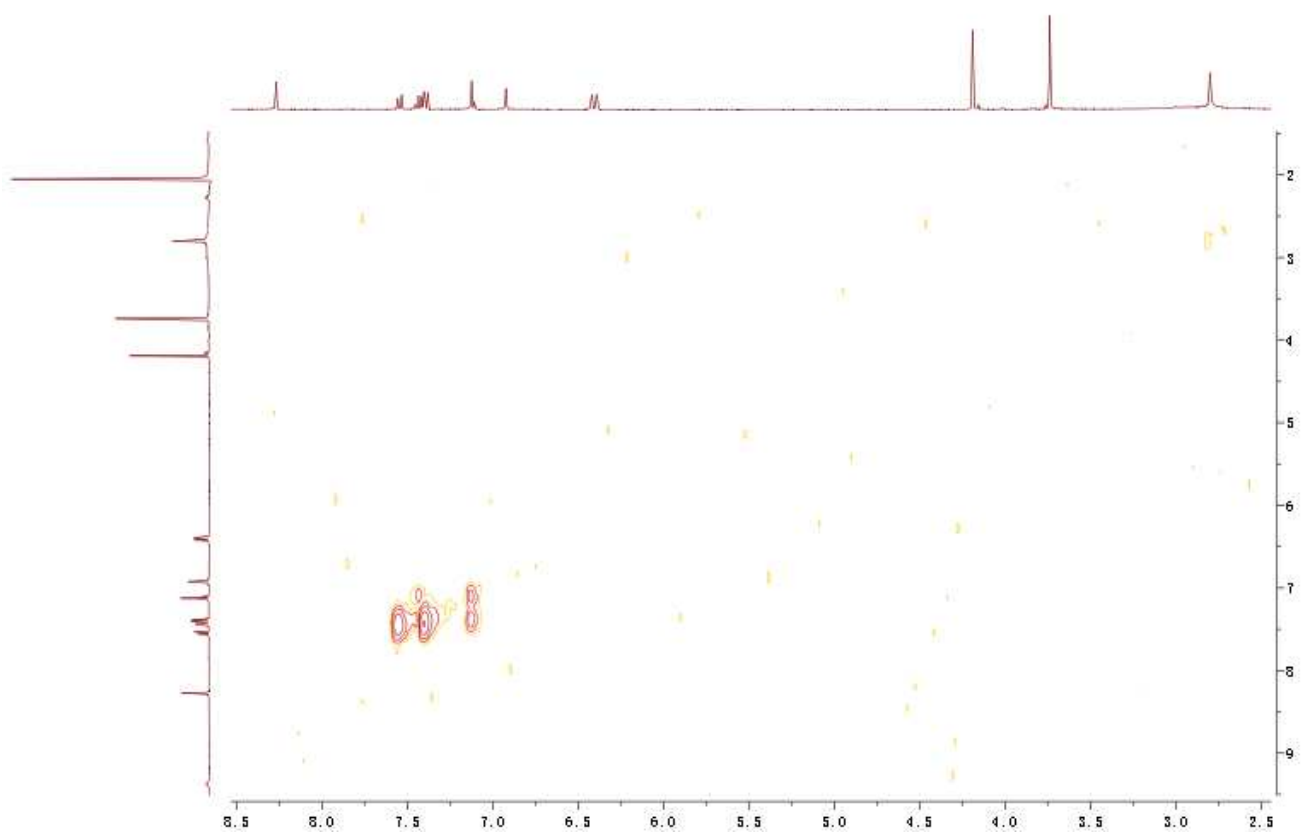

Figure S49. The HRESIMS of compound $\mathbf{2 3}$ 
Intens ( $\times 10.000 .000)$

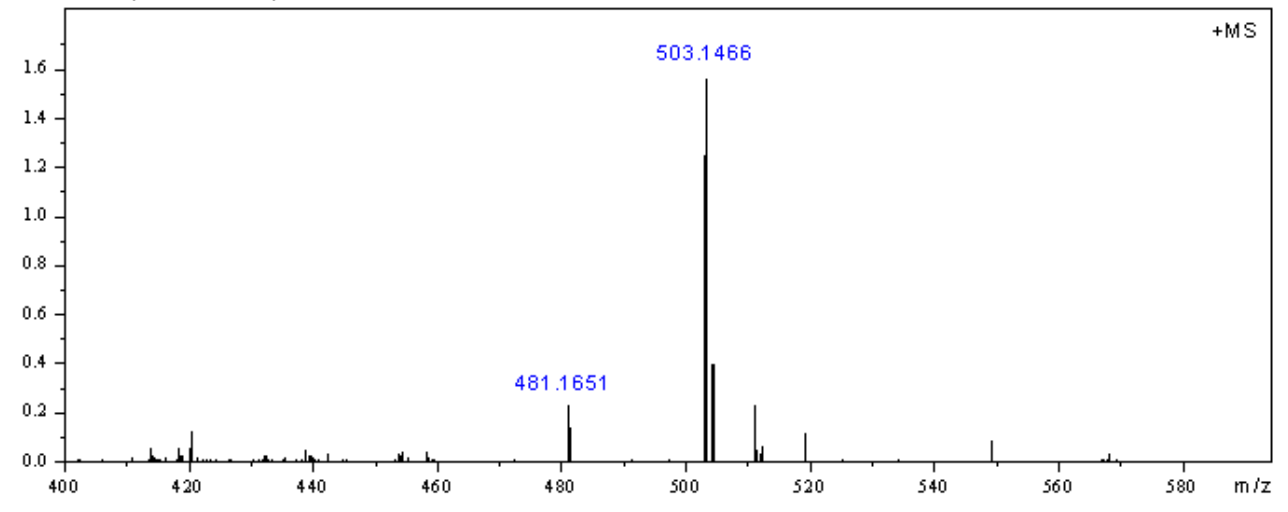


Figure S50. The ${ }^{1}$ H-NMR spectrum of compound 24 in Acetone- $d_{6}$

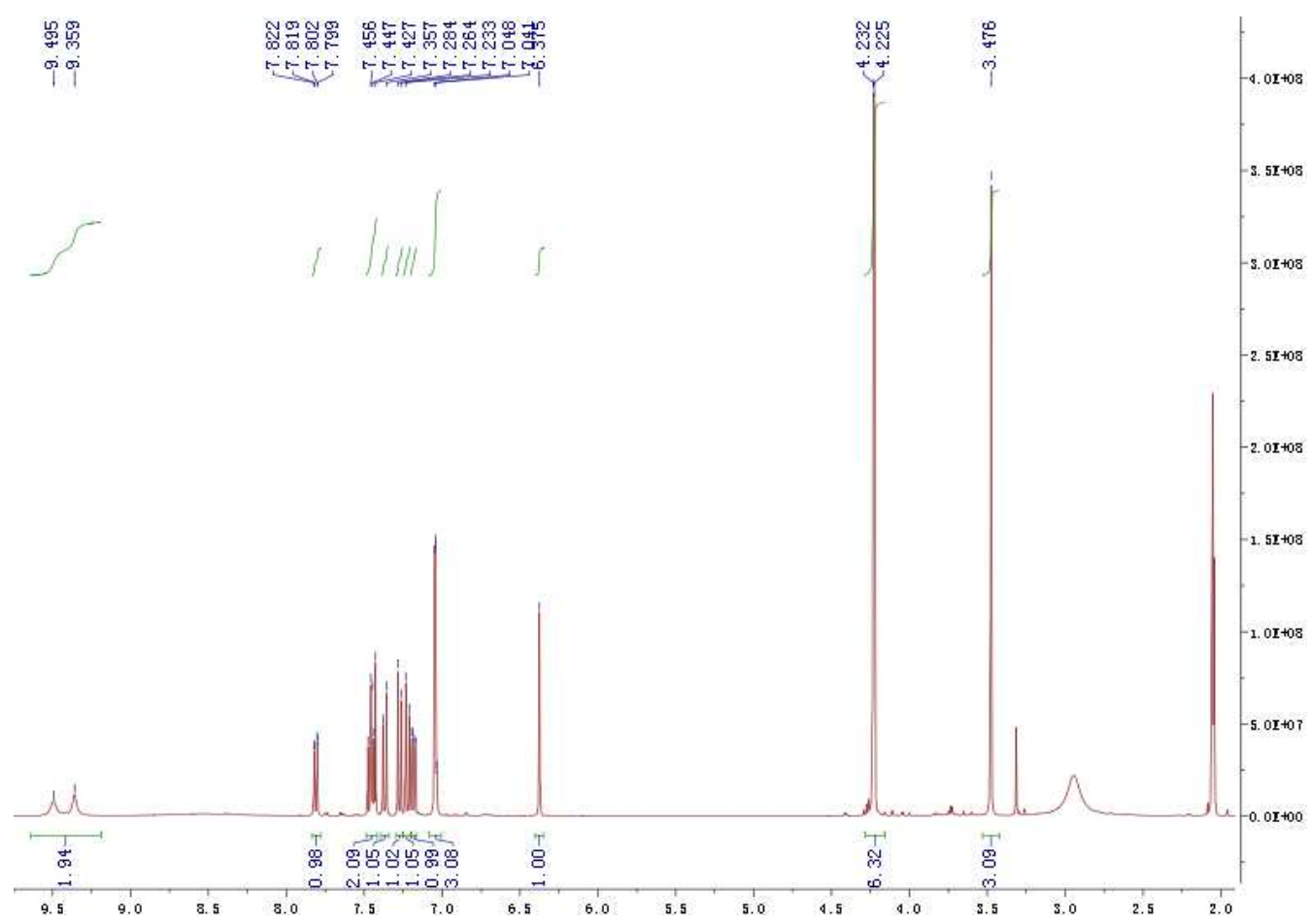

Figure S51. The ${ }^{13} \mathrm{C}-\mathrm{NMR}$ spectrum of compound 24 in Acetone- $d_{6}$

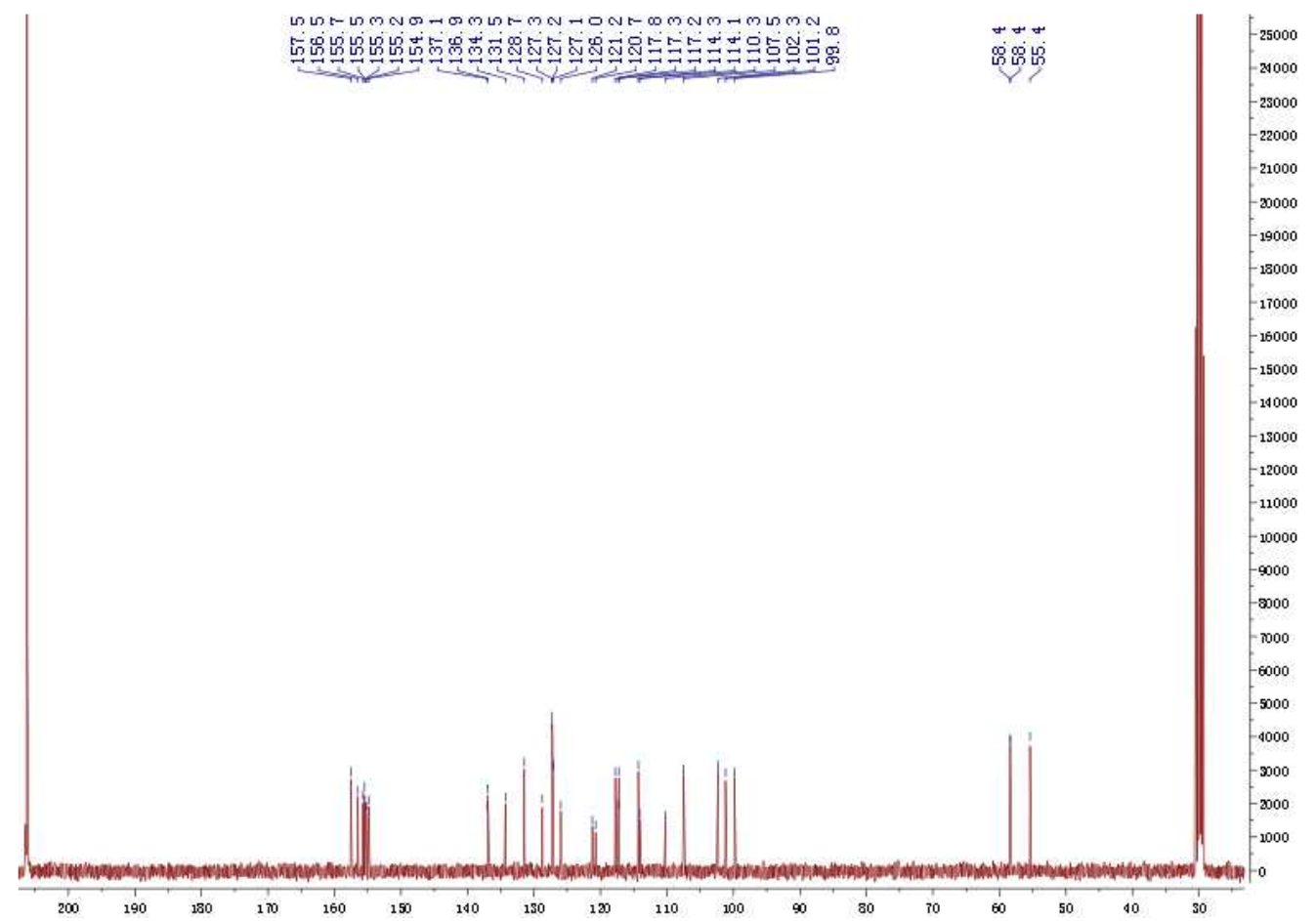


Figure S52. The DEPT spectrum of compound 24 in Acetone- $d_{6}$

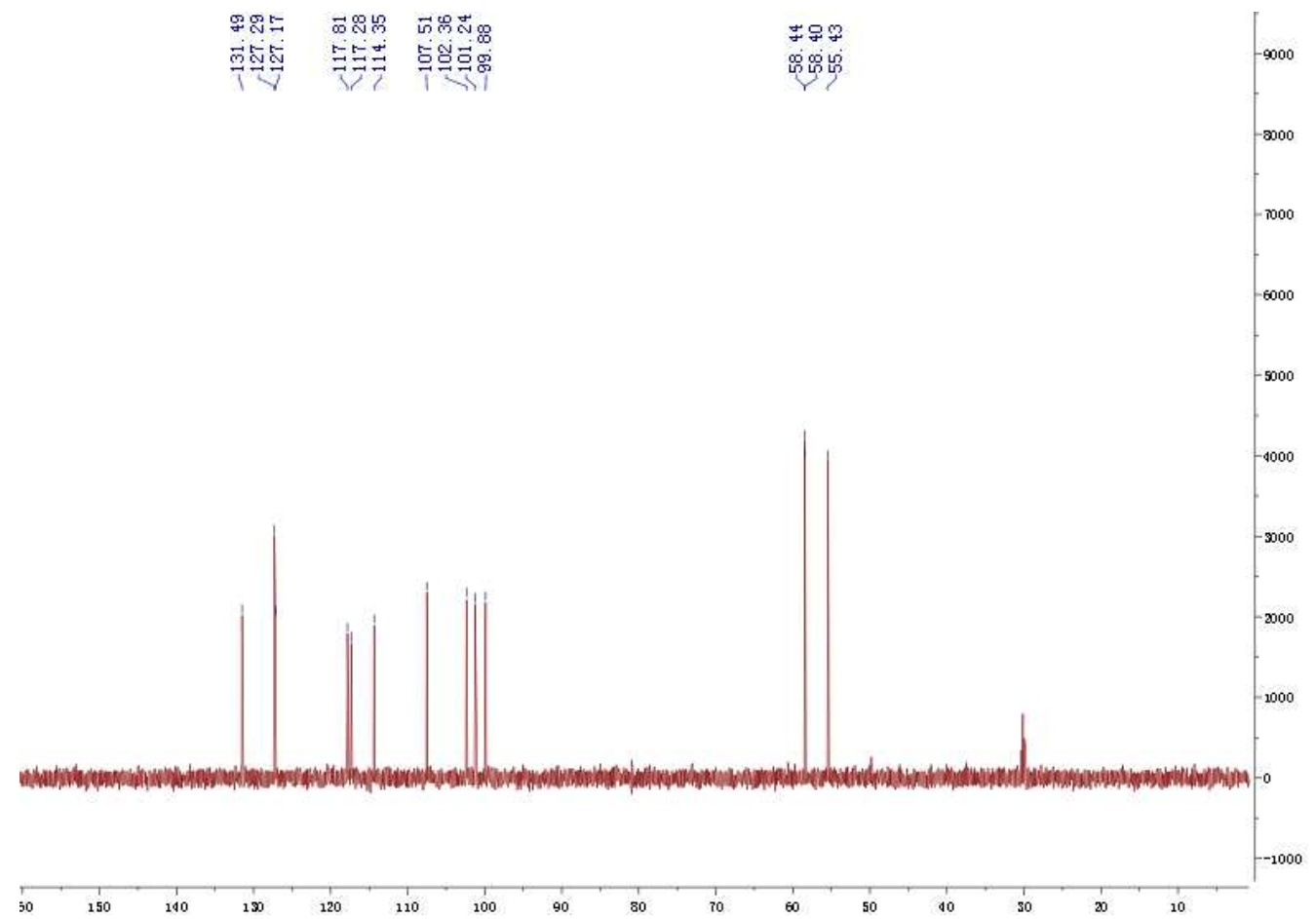

Figure S53. The HSQC spectrum of compound 24 in Acetone- $d_{6}$

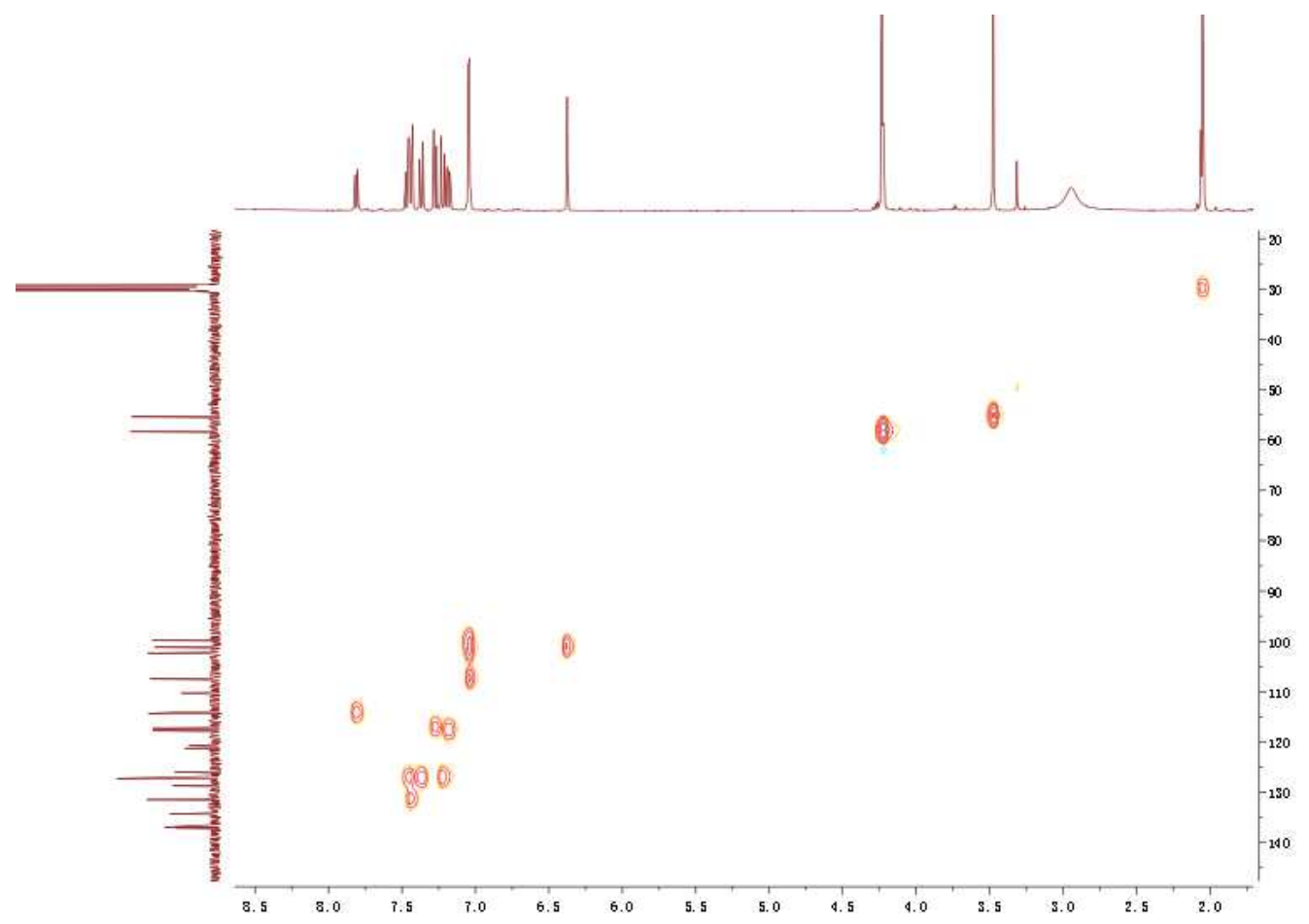


Figure S54. The HMBC spectrum of compound 24 in Acetone- $d_{6}$

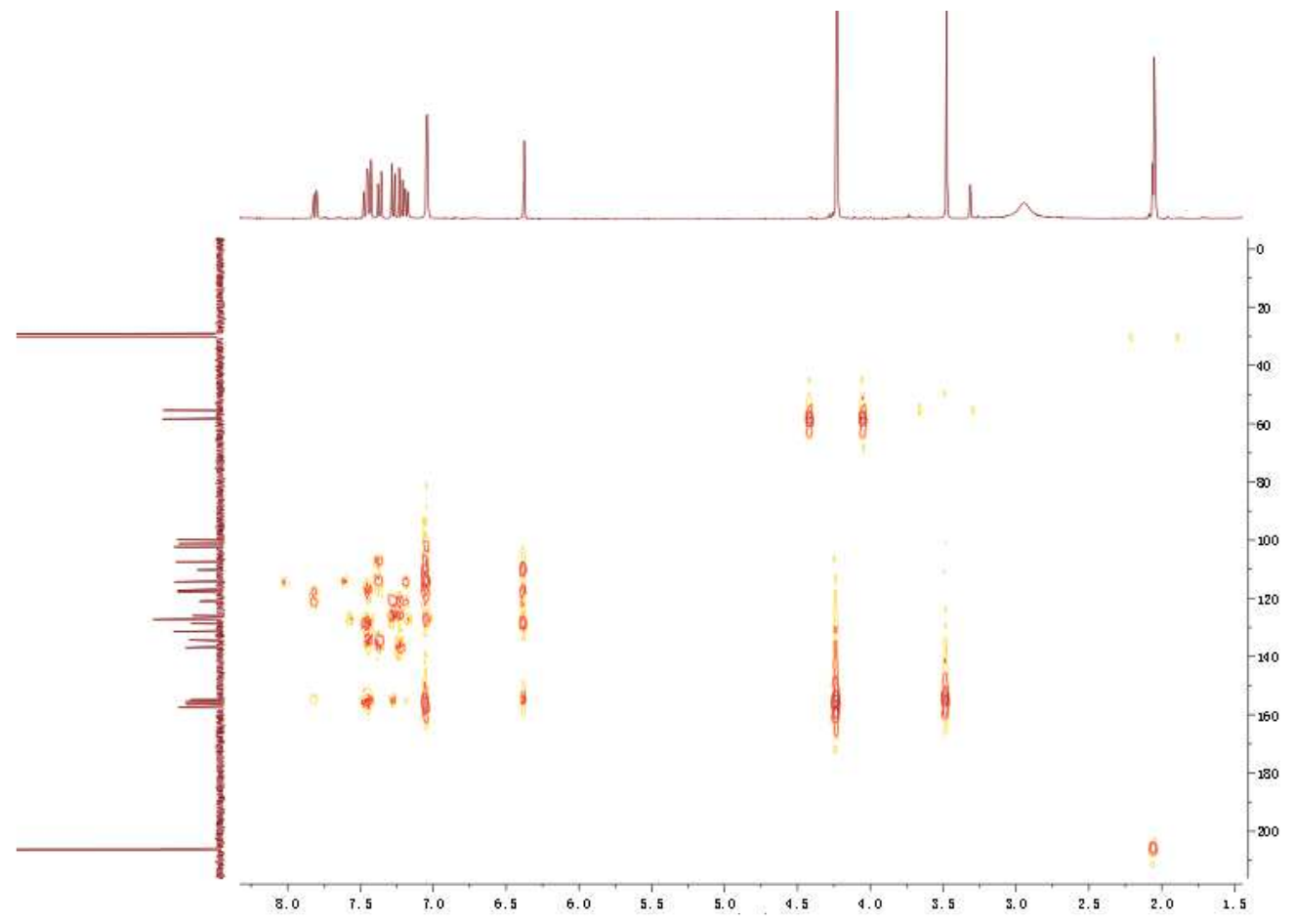

Figure S55. The ${ }^{1} \mathrm{H}-{ }_{-}^{1} \mathrm{H}$ COSY spectrum of compound 24 in Acetone- $d_{6}$

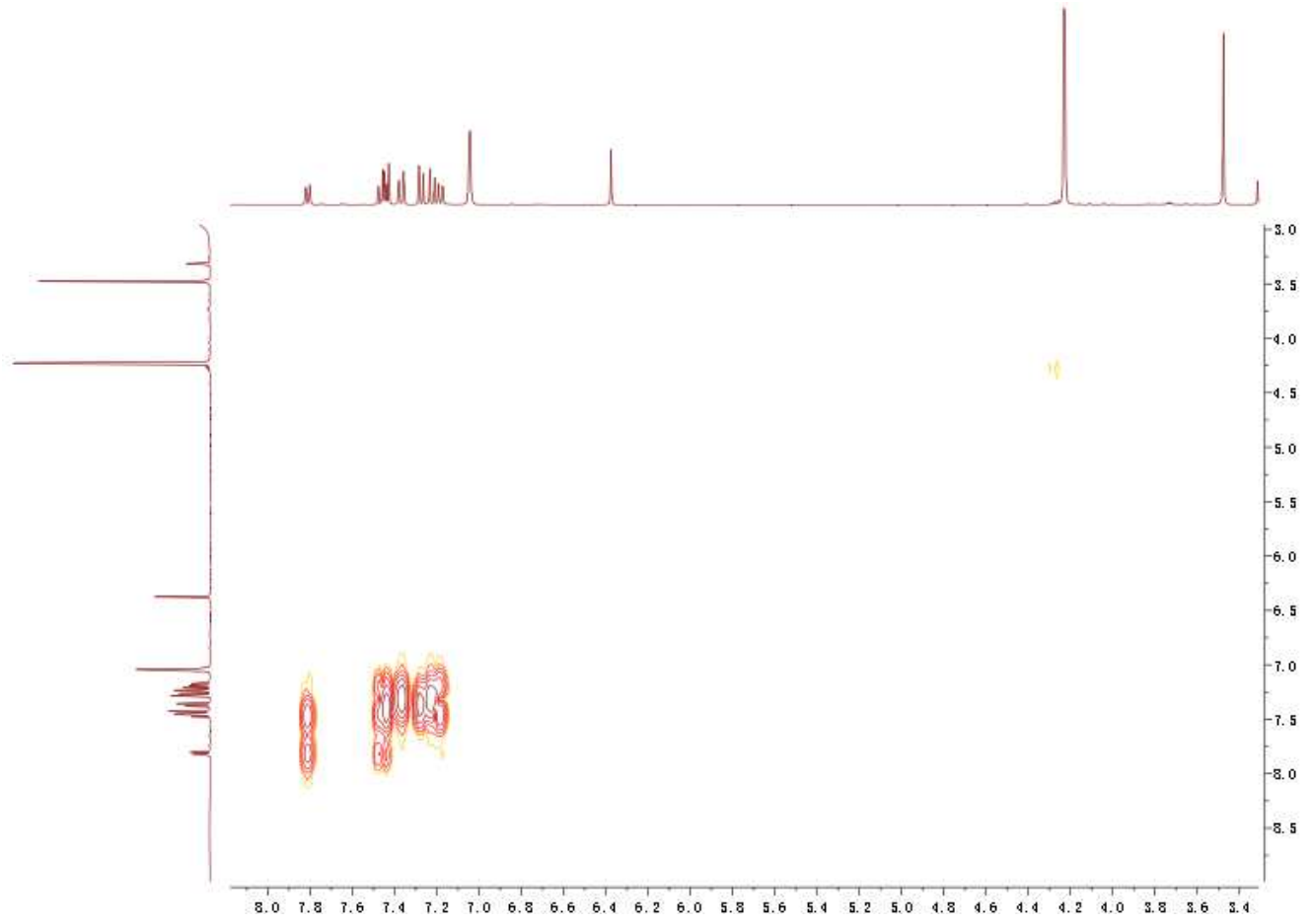


Figure S56. The HRESIMS of compound 24

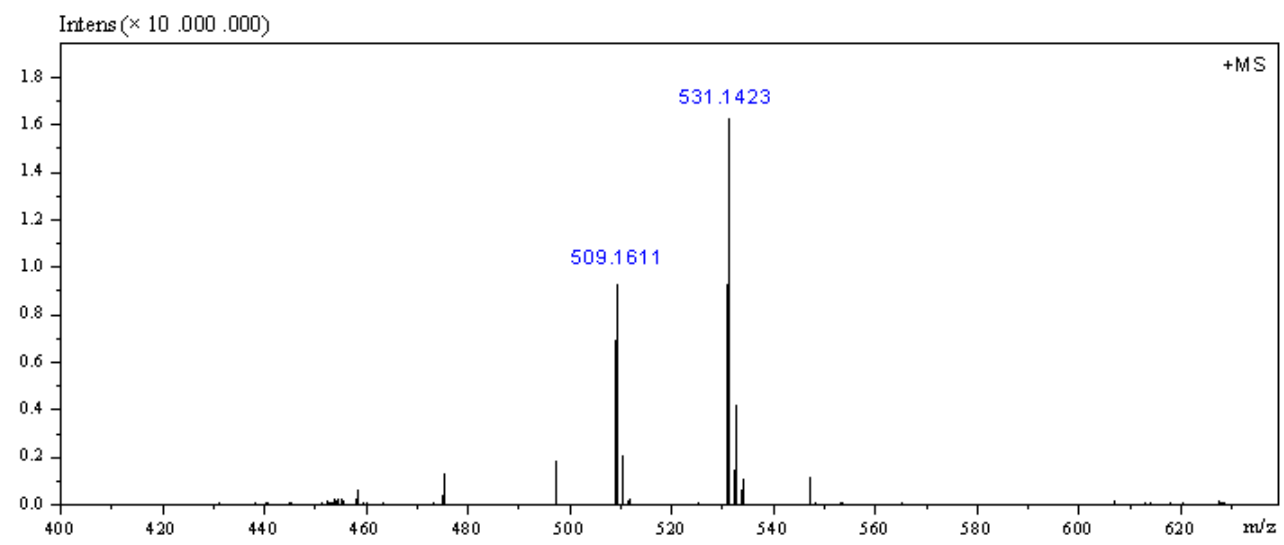

S57. The procedure of calculation ECD

The absolute configurations of compounds $\mathbf{1}$ and $\mathbf{2}$ were determined by TDDFT quantum chemical calculations of their ECD spectra and specific rotations. The $(S)$ configuration of compound $\mathbf{1}$ was selected for all the calculations, and calculated data for the $(R)$ enantiomer 2 were obtained by direct inverse of the calculated data of $\mathbf{1}$. Conformational analysis was carried out via Monte Carlo searching using a molecular mechanism with the MMFF94 force field in the SPARTAN 08 software package. ${ }^{41}$ The results showed the lowest energy conformers with relative energy with in a 2.0 $\mathrm{kcal} / \mathrm{mol}$ energy. Subsequently, the conformers were reoptimized using DFT at the B3LYP/aug-cc-pVDZ level in MeOH (PCM solvent model) by the GAUSSIAN 09 program. ${ }^{42}$ The B3LYP/aug-cc-pVDZ-SCRF harmonic vibrational frequencies were also calculated to confirm their stability. The energies, oscillator strengths, and rotational strengths (velocity) of the first 60 electronic excitations were calculated using the TDDFT methodology at the B3LYP/aug-cc-pVDZ level in $\mathrm{MeOH}$ (PCM solvent model). The ECD spectra were simulated by the overlapping Gaussian function (half the bandwidth at $1 / \mathrm{e}$ peak height, $\sigma=0.8 \mathrm{eV}$ ). ${ }^{43}$ Wavelengths of the calculated ECD spectra were shifted by $+50 \mathrm{~nm}$ to match the experimental wavelengths. To obtain the final conformationally averaged data, the simulated spectra of the two lowest energy conformers were averaged according to the Boltzmann distribution theory and their relative Gibbs free energy $(\Delta G)$. To further 
confirm the ECD assignments, specific rotations were calculated in the B3LYP/aug-cc-pVDZ-SCRF (MeOH) level based on the DFT optimized geometries.

S58. The antifungal bioassay

The antifungal bioassays were conducted following the National Center for Clinical Laboratory Standards (NCCLS) recommendations. Targeted microbes (three to four colonies) were prepared from broth culture $\left(28^{\circ} \mathrm{C}\right.$ for $\left.48 \mathrm{~h}\right)$, and the final spore suspensions of fungi were $10^{4}$ mycelial fragments $/ \mathrm{mL}$. Test compounds $(1 \mathrm{mg} / \mathrm{mL}$ as the stock solution in DMSO and serial dilutions) were transferred to a 96-well clear plate in triplicate, and the suspension of the test organisms was added to each well achieving a final volume of $200 \mu \mathrm{L}$. The plates were stored in controlled-environment cabinets from 4 to 14 days, depending on the assay, and mycelial growth was then assessed. After incubation, the absorbance at $492 \mathrm{~nm}$ was measured with a microplate reader. The MIC was defined as the lowest test concentration that completely inhibited the growth of the test organisms. Prochloraz was used as a positive control. 